\title{
Regional impacts of black carbon morphologies on aerosol-radiation interactions: A comparative study between the US and China
}

Jie Luo ${ }^{1,2}$, Zhengqiang $\mathrm{Li}^{1}$, Chenchong Zhang ${ }^{3}$, Qixing Zhang ${ }^{2, *}$, Yongming Zhang ${ }^{2}$, Ying Zhang ${ }^{1}$, Gabriele Curci ${ }^{5,6}$, and Rajan K. Chakrabarty ${ }^{3,4}$

${ }^{1}$ State Environment Protection Key Laboratory of Satellite Remote Sensing, Aerospace Information Research Institute, Chinese Academy of Sciences, Beijing 100101, China

${ }^{2}$ State Key Laboratory of Fire Science, University of Science and Technology of China, Hefei, Anhui 230026, China

${ }^{3}$ Center for Aerosol Science and Engineering, Department of Energy, Environmental and Chemical Engineering, Washington University in St. Louis, St. Louis, MO 63130, USA

${ }^{4}$ McDonnell Center for the Space Sciences, Washington University in St. Louis, St. Louis, MO 63130, USA

${ }^{5}$ Department of Physical and Chemical Sciences, University of L'Aquila, L'Aquila, Italy

${ }^{6}$ Center of Excellence in Telesening of Environment and Model Prediction of Severe Events (CETEMPS), University of L'Aquila, L'Aquila (AQ), Italy

Correspondence: Qixing Zhang (qixing@ustc.edu.cn)

Abstract. Black carbon (BC) is one of the dominant absorbing aerosol species in the atmosphere. It normally has complex fractal-like structures due to the aggregation process during combustion. A wide range of aerosol-radiation interactions (ARI) of $\mathrm{BC}$ has been reported throughout experimental and modeling studies. One reason for the large discrepancies among multiple studies is the application of the over-simplified spherical morphology for BC in ARI estimates. Here, we employ a regional chemical transport model coupled with a radiative transfer code which utilizes the non-spherical BC optical simulations to reevaluate the effects of particles' morphologies on BC ARI. Anthropogenic activities and wildfires are two major sources of BC emissions. Therefore, we choose four typical polluted cities in East China which are dominated by urban emissions, and three locations in the northwest US that are dominated by fire emissions in this study. Our modeling results show that spherical BC models overestimate the aerosol optical depth (AOD) at $550 \mathrm{~nm}$ wavelength up to 0.03 and 0.15 at typical polluted cities in East China and fire regions in the northwest US, respectively, than fractal BC models with a fractal dimension $\left(D_{f}\right)$ of 1.8. Besides, spherical BC model underestimates BC aerosol absorption optical depth (AAOD) at $450 \mathrm{~nm}$ up to 0.016 and 0.04 at typical polluted cities in East China and fire sites in the US, respectively, than the fractal BC model. BC morphologies have relatively small impacts on the single scattering albedo (SSA) and extinction Ångström exponent (EAE), while these morphological effects on the absorption Ångström exponent (AAE) are rather significant. The spherical BC models underestimate AAE by approximately 0.17 at 450 and $850 \mathrm{~nm}$ wavelength pair than the fractal counterparts. Besides, $\mathrm{BC}$ morphologies have nonnegligible impacts on the BC ARI. The calculated mean ARI using the spherical BC model is approximately $3.47-4.45$ $\mathrm{Wm}^{-2}$ at typical polluted cities in China, while the values increase to approximately $3.83-4.92 \mathrm{Wm}^{-2}$ when using the fractal aggregate model, and the relative variations are approximately $10.4 \%-15.3 \%$. The mean BC ARI increases from approximately $4.91-6.61 \mathrm{Wm}^{-2}$ to $5.52-7.05 \mathrm{Wm}^{-2}$ and the relative variations for BC ARI are approximately $6.2 \%-6.9 \%$ 
when we modify the $\mathrm{BC}$ from spheres to fractal aggregates with a $D_{f}$ of 1.8 in the northwest US. Therefore, the effects of BC morphologies on the regional radiative effects should be carefully evaluated in different regions.

\section{Introduction}

Black carbon (BC), as the main absorbing aerosol in the atmosphere, exerts a positive radiative forcing, and lofts smoke plumes (Buseck and Buseck, 2000; Streets et al., 2006; Moosmüller et al., 2009). However, there are still large uncertainties in evaluating the $\mathrm{BC}$ radiative effects. An important cause of the discrepancy is BC's complex morphology. BC morphologies are commonly simplified as homogeneous spheres in climate modeling. However, many studies have shown that BC particles, especially those nascent ones, have fractal-like structures. The spherical assumption for BC can lead to a large deviation from the field measurement data and non-spherical simulated results (Chakrabarty et al., 2007; Luo et al., 2018c; He et al., 2015; Liu and Mishchenko, 2005; Luo et al., 2018d; Mishchenko et al., 2016a; Luo et al., 2021b). Based on the sampled BC images, researchers found that the shape of uncoated $\mathrm{BC}$ aggregates can be fitted well by a fractal law with monomer number $\left(N_{s}\right)$, mean monomer radius $(R)$, fractal prefactor $\left(k_{0}\right)$, fractal dimension $\left(D_{f}\right)$ and the radius of gyration $\left(R_{g}\right)$ (Mishchenko et al., 2002; Sorensen, 2011; Luo et al., 2021a):

$N_{s}=k_{0}\left(\frac{R_{g}}{R}\right)^{D_{f}}$

Previous studies have shown that aggregated particle models are more realistic to reproduce the optical measurement results (Bi et al., 2018; Luo et al., 2019, 2018b). Some studies have used the non-spherical BC models to investigate the radiative properties of BC (Wu et al., 2015; Liu et al., 2015a; Liu and Mishchenko, 2005; Yin and Liu, 2010; Teng et al., 2019; Luo et al., 2018a; Kahnert, 2010a). However, extremely limited number of studies have evaluated the ARI of non-spherical BC in regional or global climate models. Kahnert (2010b) has made efforts to simulate the radiative properties of freshly emitted BC using the Multiple-scale Atmospheric Transport and CHemistry (MATCH) model. That study assumed a fixed solar zenith angle (SZA) and restricted the modeling region in Western Europe. However, expanding the modeling range to regions with different emission characteristics is important to understand the effects of BC sources on aerosol-radiation interactions (ARI).

The direct radiative effect (DRE) was widely used to evaluate the climate effects of aerosol (Bond et al., 2013; Saleh et al., 2015). IPCC (2014) suggested using the new terminology of ARI instead of DRE. Thus, in this work, we use the terminology of ARI to replace DRE. A global mean BC ARI of $+1.1 \mathrm{~W} \mathrm{~m}^{-2}$ has been reported by Bond et al. (2013). However, the BC ARI values estimated based on in-situ optical measurements in some regions are much larger than the rest. $\mathrm{BC}$ emissions in China roughly account for one-fourth of its global anthropogenic emission budget (Streets et al., 2001). East China, a typical polluted region, is dominated by anthropogenic emissions (Zhang et al., 2009; Li et al., 2017a). Therefore, BC ARI in East China has gained increasing interest.

Besides the anthropogenic sources, wildfires significantly contribute the regional BC emissions. The extremely-high BC ARI can be found in those fire sites. Recent studies have shown that $\mathrm{BC}$ emitted from fire sites can also loft the surrounding atmospheric aerosols to the upper troposphere and lower stratosphere (Yu et al., 2019). Thus, the investigation of BC ARI in 
these regions is important to understand the detailed plume dynamics and the warming effects of BC. The northwest US, as one of the most frequent wildfire regions in the world, has also been investigated in addition to East China.

In this work, we employed Weather Research and Forecasting coupled to Chemistry (WRF-Chem) to simulate the aerosol mass concentrations. Note here that WRF-Chem assumes aerosols to be spherical. Therefore, the radiative parameters of aggregated models were calculated offline using an optical module, Flexible Aerosol Optical Depth (FlexAOD). We calculated the ARI at the top of the atmosphere (TOA) using the radiative transfer model (libRadtran) after the particles' optical properties were calculated. Among all the radiative parameters, we investigated aerosol optical depth (AOD), aerosol absorption optical depth (AAOD), extinction Ångström exponent (EAE), absorption Ångström exponent (AAE), single-scattering albedo (SSA), and ARI at the TOA, which were widely used in remote sensing and climate effect evaluation.

\section{Aerosol distribution simulation}

In this work, WRF-Chem version 4.1.3 was used to simulate the transport of atmospheric species. Two areas were selected to represent the BC sources with different emission characteristics. East China, a main polluted region in the world, represented the typical polluted urban region. It consists of 115 east-west grids and 105 south-north grids centered at $112.00^{\circ} \mathrm{E}, 35.00^{\circ} \mathrm{N}$ with a grid resolution of $18 \mathrm{~km}$. North America, one of the most frequent forest fire regions in the world, was also investigated in this work. The fire region consists of 120 east-west grids and 120 south-north grids centered at $121.48^{\circ} \mathrm{W}, 39.89^{\circ} \mathrm{N}$ with a grid resolution of $4 \mathrm{~km}$. The schematics of the two studied regions are shown in Figure S1. Both regions have 33 vertical layers above the ground, with a top pressure of $50 \mathrm{hPa}$.

We used the Model of Emissions of Gases and Aerosols from Nature (MEGAN) to compute the biogenic emissions over two regions (Guenther et al., 1994, 2006). The anthropogenic emission inventory is vital to estimate the aerosol distributions. The anthropogenic inventory in the mainland of China was compiled by the multi-resolution emission inventory for China (MEIC) (Li et al., 2014; Liu et al., 2015b) for East China in the year 2016. We used MIX anthropogenic inventory for the region outside China (Li et al., 2017b). The Regional Acid Deposition Model version 2 (RADM2) atmospheric chemical mechanism (Stockwell et al.) and the Model Aerosol Dynamics for Europe with the Secondary Organic Aerosol Model (MADE/SORGAM) were applied in this study (Seinfeld et al., 2001; Ackermann et al., 1998). Fast-J photolysis scheme (Wild et al., 2000) was used to simulate the photolysis rates. The physical scheme options in WRF-Chem are shown in Table S1.

The EDGAR-HTAP anthropogenic inventory for 2010 was used in the North American region. MOSAIC aerosol scheme (Zaveri and Peters, 1999; Zaveri et al., 2008) and CBM-Z (carbon bond mechanism) photochemical mechanism (Zaveri and Peters, 1999) was used in forest fire region simulation. The Fire emission was provided by the Fire INventory from NCAR (FINN) (Wiedinmyer et al., 2011). Note here EDGAR-HTAP anthropogenic inventory and FINN were provided for the MOZART chemical mechanism, so we manually mapped the emission for the MOZART chemical mechanism to the CBM-Z chemical mechanism based on the study of Emmons et al. (2010). The National Center for Environmental Prediction (NCEP) Global Forecast System's final gridded analysis data set was used to provide the meteorological initial and boundary conditions. The chemical initial and boundary conditions were obtained from the Model for Ozone and Related Tracer, version 4 (MOZART-4). 


\section{Calculating the ARI of BC}

\subsection{The morphology of $\mathrm{BC}$}

In this work, we only consider externally mixed $\mathrm{BC}$ aerosols, which is commonly represented by fractal structures. $D_{f}$ is a key parameter to describe the compactness of fractal BC (Wang et al., 2017; Yuan et al., 2019), and the BC morphology can vary from a chain-like structure to a spherical structure if $D_{f}$ increase from approxiamtely 1.8 to 3 . The freshly emitted BC generally exhibits a fluffy structure with a $D_{f}$ of approximately 1.8 (Heinson et al., 2010, 2017). The laboratory measurements also showed that the freshly emitted BC generally presents a small $D_{f}$. Chakrabarty et al. (2006) have shown that $D_{f}$ of BC emitted from wildland fuels generally exhibits a range of $1.67-1.83$. A $D_{f}$ range of $1.6-1.9$ was observed for BC produced from diesel combustion (Wentzel et al., 2003). China et al. (2013) indicated that the BC freshly emitted from wildfire generally exhibits a $D_{f}$ range of $1.74-1.92$. However, a more compact structure was commonly observed for BC in the atmosphere with the particle aging (Li et al., 2003; Adachi et al., 2014; Chen et al., 2016; Adachi et al., 2007). A $D_{f}$ range of $2.2-2.4$ was observed in the study of Adachi et al. (2007). The fractal structures with a larger are widely used to describe the BC with more compact structures (Adachi et al., 2007). Chakrabarty et al. (2006) further showed that the $D_{f}$ of aged BC can reach up to 2.6. To represent both fluffy and compact $\mathrm{BC}, D_{f} \mathrm{~s}$ of 1.8, 2.2, and 2.6 were considered. Even though $k_{0}$ was also measured in a wide range in the atmosphere, its impact was relatively small, so we assumed a fixed $k_{0}$ of 1.2 in this work. The typical morphologies of fractal BC are shown in Figure 1.

The volume-mean particle radius was commonly used to describe the size of non-spherical BC. $N_{s}$ and $R$ are two important parameters to describe the volume-mean particle radius of BC. Previous studies have observed a range of approximately $8-$ $57 \mathrm{~nm}$ for BC monomer radius (Eggersdorfer and Pratsinis, 2012; Mikhailov et al., 2006; KOylU and Faeth, 1992; Lee et al., 2002), while Kahnert and Kanngießer (2020) further showed that the typical range is approximately $10-25 \mathrm{~nm}$. In this work, we assumed a fixed monomer radius of $20 \mathrm{~nm}$. We considered an $N_{s}$ range $1-1000$ to represent BC with different sizes. The volume-mean particle radius $\left(r_{p}\right)$ can be calculated using:

$r_{p}=R N_{s}^{1 / 3}$

We must clarify that $\mathrm{BC}$ can internally mix with other compositions, and the morphology can become more complex (Wang et al., 2021, 2017). However, we mainly focus on the freshly emitted BC, and only consider externally mixed BC. Further investigations would be performed for more complex internally mixed $\mathrm{BC}$ in the future.

\subsection{The refractive index and size distribution of $\mathrm{BC}$}

BC refractive index shows a little spectral dependence (Chang and Charalampopoulos, 1990), while it doesn't vary largely with wavelengths in the short wavelength range, and the absorption Ångström exponent is approximately 1 (Liu et al., 2018; Lack and Cappa, 2010). Therefore, BC refractive index is commonly assumed to be spectrally invariant (Bond and Bergstrom, 2006). The suggested BC refractive index values by Bond and Bergstrom (2006) were commonly used. In this work, the median value of $1.85+0.71 i$ was used, as it was widely used in many regional and global climate models (e.g. WRF-Chem). The size 
distribution of $\mathrm{BC}$ and $\mathrm{OC}$ also suffers large uncertainties from different fuels and conditions. The size distribution of BC is commonly fitted by a lognormal size distribution with a geometric mean radius $\left(r_{g}\right)$, and a geometric standard deviation $\left(\sigma_{g}\right)$ (Schwarz et al., 2008; Mishchenko et al., 2016b):

$n\left(r_{p}\right)=\frac{N_{0}}{\sqrt{2 \pi} r_{p} \ln \left(\sigma_{g}\right)} \exp \left[-\left(\frac{\ln \left(r_{p}\right)-\ln \left(r_{g}\right)}{\sqrt{2} \ln \left(\sigma_{g}\right)}\right)^{2}\right]$

where $r_{p}$ is the aerosol radius, $N_{0}$ is the total number concentration calculated by the mass concentration obtained from WRFChem by assuming BC mass density, $r_{g}$, and $\sigma_{g}$. The details about the calculation of $N_{0}$ are shown in Curci (2012). Firstly, by assuming $N_{0}=1$, we created a look-up table for different $r_{g}$ and $\sigma_{g}$, and then the optical properties were obtained by plugging in the tested BC's $r_{g}$ and $\sigma_{g}$.

$\mathrm{BC}$ geometric mean radius of $0.05-0.06 \mu \mathrm{m}$ is frequently observed by instruments and widely assumed in numerical studies (Alexander et al., 2008; Coz and Leck, 2011; Reddington et al., 2013; Liu et al., 2018). In this work, BC geometric mean radius was assumed to be $0.05 \mu \mathrm{m}$. $\sigma_{g}$ was assumed to be a fixed value of 1.6. We used the volume-equivalent radius of non-spherical $\mathrm{BC}$ to characterize the $\mathrm{BC}$ size. The density of $\mathrm{BC}$ was assumed to be $1.8 \mathrm{gm}^{-3}$ based on the suggested values by Bond and Bergstrom (2006).

\subsection{BC radiative properties}

In this work, BC radiative properties were calculated using the multiple sphere T-matrix method (MSTM) (Mackowski and Mishchenko, 2011, 1996). Using MSTM, the extinction efficiency $\left(Q_{e x t}\right)$, scattering efficiency $\left(Q_{s c a}\right)$, and phase function $(P)$ can be directly calculated. Then, extinction cross-section $\left(C_{\text {ext }}\right)$ and scattering cross-section $\left(C_{s c a}\right)$ were obtained using:

$C_{e x t}=Q_{e x t} \pi r_{p}^{2}$

$C_{s c a}=Q_{s c a} \pi r_{p}^{2}$

where $r_{p}$ represents the volume-equivalent radius of non-spherical BC. In this work, we have calculated the optical properties of BC with a $N_{s}$ range of $1-1000$. Bulk extinction cross-section $\left.\left(<C_{e x t}\right\rangle\right)$, scattering cross-section $\left.\left(<C_{s c a}\right\rangle\right)$ and phase function $<\mathrm{P}>$ were calculated using the following equations:

$$
\begin{aligned}
& <C_{e x t}>=\int_{r_{\text {min }}}^{r_{\max }} C_{e x t}\left(r_{p}\right) n\left(r_{p}\right) d r \\
& <C_{s c a}>=\int_{r_{\min }}^{r_{\max }} C_{s c a}\left(r_{p}\right) n\left(r_{p}\right) d r
\end{aligned}
$$


$<P(\theta)>=\sum_{S=1}^{S_{\max }} \alpha_{S} P_{S}(\cos \theta)$

where $\theta$ is the scattering angle, $P_{S}$ are generalized spherical functions, $\alpha_{S}$ are the expansion coefficients, and $S_{\text {mas }}$ is the order of truncation of the expansion. In this work, we used the pmom code in the Libradtran software to calculate the Legendre expansion coefficients. The asymmetry parameter $(g)$ was calculated using:

$g=\int_{0}^{\pi} \cos \theta<P(\theta)>\sin \theta d \theta$

The radiative properties of fractal $\mathrm{BC}$ and $\mathrm{BC}$ spheres were calculated at $300 \mathrm{~nm}-4000 \mathrm{~nm}$ wavelengths. The step size of $\Delta \lambda=50 \mathrm{~nm}$ was chosen when $\lambda$ is less than $1000 \mathrm{~nm}$, while $\Delta \lambda=200 \mathrm{~nm}$ was selected for $1000 \mathrm{~nm} \leq \lambda \leq 2000 \mathrm{~nm}$, and $\Delta \lambda=$ $400 \mathrm{~nm}$ when $\lambda \geq 2000 \mathrm{~nm}$. We created look-up tables for $\left\langle C_{a b s}\right\rangle,\left\langle C_{s c a}\right\rangle$, and the Legendre expansion coefficients of phase functions for each $\sigma_{g}$ and $r_{g}$. Thus, the optical properties of BC can be obtained by interpolating the look-up tables.

\subsection{Flexible Aerosol Optical Depth (FlexAOD)}

The aerosol mass concentrations from WRF-Chem were inputted into an optical software FlexAOD (Flexible Aerosol Optical Depth) (Curci, 2012; Curci et al., 2015) for the calculation of the aerosol radiative properties. FlexAOD is an optical postprocessing tool for the chemistry-transport model, and it started as a tool for the Geos-Chem model. We have made some modifications on FlexAOD to make it accommodate the WRF-Chem outputs. We firstly mapped the aerosols from WRF-Chem into 5 categories: BC, organic carbon(OC), inorganic salt (INS), sea salt (SA), and dust (DST). The mapping details are shown in Tables S2 - S3. After the WRF-Chem species were mapped, the size distribution, refractive indices, and hygroscopic growth factors were then assigned.

The FleAOD firstly reads the aerosol mass concentrations from WRF-Chem, then transforms to aerosol volume concentrations based on the assigned mass densities. Based on the assigned normalized size distributions, we can calculate the number concentration $\left(N_{0}\right)$ of each aerosol. FlexAOD pre-calculates the optical properties of each aerosol by assuming $N_{0}=1$ with the assumed size distributions. The total scattering/extinction coefficients can be obtained by multiplying the pre-calculated scattering/extinction cross-sections with the number concentrations. The total phase function is identical to the pre-calculated phase function by assuming $N_{0}=1$. In FlexAOD, aerosol shapes were assumed to be spherical and the corresponding optical properties of each aerosol species were calculated using the Mie code provided by Mishchenko et al. (1999), and the bulk optical properties were then calculated by combining an assembly of aerosols.

FlexAOD assumed that the $\mathrm{BC}$ shape was spherical. To consider the non-spherical structures, $\mathrm{BC}$ optical properties were overwritten using the look-up tables created in Section 3.3. As described in Section 3.3, we have created look-up tables for 
non-spherical BC for different size distributions. Thus, if the size distribution of $\mathrm{BC}$ is assigned, the optical properties of $\mathrm{BC}$ with a normalized size distribution can be determined by interpolating the look-up tables. Once the number concentration is calculated, we can determine the total optical properties.

Apart from BC, the physical properties of other chemical species were also specified. We used the OC refractive indices suggested by Highwood (2009). The density of OC varies from different conditions. The density of the oxidized organic aerosol was reported to be approximately $1.3 \mathrm{~g} \mathrm{~cm}^{-3}$ (Cross et al., 2007), while Nakao et al. (2013) reported that the density of OC with lower oxidation was approximately $1-1.2 \mathrm{~g} \mathrm{~cm}^{-3}$. For freshly formed OC, $0.9-1.1 \mathrm{~g} \mathrm{~cm}^{-3}$ was used by Liu et al. (2017). In this work, the density of OC was assumed to be $1.2 \mathrm{~g} \mathrm{~m}^{-3}$. OC size is also commonly fitted by a lognormal size distribution. In the study of He et al. (2016) and Dentener et al. (2006), $r_{g}=0.03 \mu \mathrm{m}$ and $r_{g}=0.075 \mu \mathrm{m}$ were assumed for hydrophobic and hydrophilic OC, respectively. In this study, all OC was assumed to be hydrophilic, and we assumed a $r_{g}$ of $0.075 \mu \mathrm{m}$ and a $\sigma_{g}$ of 1.6. The refractive indices of dust were identical to those used in the GOCART Model (Chin et al., 2002), and the refractive indices of other chemical species were adapted from the OPAC package (Hess et al., 1998). The physical properties are displayed in Table S4. Similar to the study of Curci et al. (2019), the hygroscopic growth factors of different aerosols were taken from the OPAC package (Hess et al., 1998). For dust, the gamma distribution was assumed: (Martin et al., 2003; Curci, 2012):

$n(r)=N_{0} r_{p}^{(1-3 b) / b} \exp \left(-\frac{r_{p}}{a b}\right)$

where $a$ and $b$ are two parameters for the distribution, and $b$ is in the range of $0-0.5$.

We must clarify that many internally mixed particles exist in the atmosphere, while in this study we mainly aim to study the morphological effects of freshly emitted particles, and more complex particles may be investigated in the future. Effective refractive indices were calculated using the volume mixing method for hydrophilic particles.

The total column SSA and AOD were calculated by FlexAOD, and AAOD was calculated by:

$\mathrm{AAOD}=\mathrm{AOD}(1-\mathrm{SSA})$

$\mathrm{AAE}$ and EAE were calculated by:

$\mathrm{AAE}=-\frac{\ln \left(\mathrm{AAOD}_{1}\right)-\ln \left(\mathrm{AAOD}_{2}\right)}{\ln \left(\lambda_{1}\right)-\ln \left(\lambda_{2}\right)}$

$\mathrm{EAE}=-\frac{\ln \left(\mathrm{AOD}_{1}\right)-\ln \left(\mathrm{AOD}_{2}\right)}{\ln \left(\lambda_{1}\right)-\ln \left(\lambda_{2}\right)}$

here $\lambda_{1}$ and $\lambda_{2}$ represent two reference wavelengths; $\mathrm{AAOD}_{1}$ and $\mathrm{AAOD}_{2}$ represent the $\mathrm{AAOD}$ at corresponding wavelengths;

$\mathrm{AOD}_{1}$ and $\mathrm{AOD}_{2}$ represent the $\mathrm{AOD}$ at corresponding wavelengths.

\subsection{ARI modeling}

The optical properties (Extinction coefficient, SSA, Asymmetric factor (ASY)) calculated using FlexAOD at each WRF-Chem grid were inputted into a radiative transfer model, libRadtran (Mayer and Kylling, 2005), to calculate the radiative fluxes at 
the top-of-the-atmosphere (TOA). The radiative transfer equation was solved by DISORT radiative transfer equation solver (Stamnes et al., 1988; Buras et al., 2011). Based on the longitude, latitude, and UTC time, libRadtran can select a standard atmosphere background and determine the solar zenith angle (SZA).. The albedo information was obtained from NASA EARTH OBSERVATIONS (NEO). Besides, we filled the missing values with the albedo provided by WRF-Chem. In this work, we just considered the ARI for clear-sky. The radiative transfer calculations were performed for each hour and then were averaged over one day. In this work, the direct radiative effects (ARI) of BC aerosol were calculated using following equations:

$\mathrm{FLUX}=\mathrm{F}^{\downarrow}-\mathrm{F}^{\uparrow}$

where $\mathrm{F}^{\downarrow}$ represents downward radiative flux and $\mathrm{F}^{\uparrow}$ represents upward radiative flux. In this work, we just considered the ARI at the TOA.

\section{Results}

\subsection{Impacts of BC morphology on AOD and AAOD}

To verify the modeling performance for the aerosol concentrations, we compared the simulated PM2.5 concentrations with observations at some monitoring sites, and the results are shown in Figure 2. In the figures, the left column represents the typical cities in China, and the right column represents the sites in North America. As shown in Figure 2, the calculated PM2.5 concentrations in China are generally consistent with the observations. Even though the simulated PM2.5 concentrations in the fire region are a little higher than the observations, the deviations are not large, and the general trends are consistent. Therefore, it is reasonable to represent the atmospheric aerosol concentrations using WRF-Chem modeling. We just compare the calculated AOD and AAOD in Beijing with observations from AErosol RObotic NETwork (AERONET), as the optical observations are limited in our simulation region. As shown in Figure 3, the calculated AAOD and AOD can generally represent the observations.

For the fire region, even though the surrounding $\mathrm{BC}$ concentrations are small, $\mathrm{BC}$ concentrations at fire sites are extremely high. In this study, we selected three fire sites to evaluate the morphological effects on the BC ARI. The positions of the selected sites are shown in Table S5, and they represent the fire sites with high aerosol concentrations. As shown in Figure 4, $\mathrm{BC}$ concentrations at fire sites can even exceed approximately $400 \mu \mathrm{g} / \mathrm{m}^{3}$, which should have a strong impact on the aerosol radiative effects. In East China, we select Beijing, Shanghai, Tianjin, and Nanjing as the typical sites to represent the polluted urban cities. As shown in Figure 4, even though maximum BC concentrations in the polluted urban cities are much smaller than the fire site, the mean BC concentrations are also high, which can reach approximately $12 \mu \mathrm{g} / \mathrm{m}^{3}$. The simulated BC concentrations generally agree with the measurements of Zhang et al. (2012) for the urban region, where BC concentrations were observed to be approximately $4-12.7 \mu \mathrm{g} / \mathrm{m}^{3}$. 
Figure 5 shows the mean $\mathrm{BC}$ AOD and $\mathrm{AAOD}$ as a percentage of the total AOD and AAOD. In typical China polluted cities, $\mathrm{BC}$ AOD accounts for approximately $4.6 \%$ - 7\% of the total AOD, while BC AOD in fire sites can account for larger than 10\% of the total AOD. At $450 \mathrm{~nm}$, in both polluted urban and fire sites, the fractions of BC AAOD are close, which is approximately $30 \%$. This means that the relative proportions of $\mathrm{BC}$ and $\mathrm{OC}$ in polluted urban sites are close to those of fire sites.

$\mathrm{BC}$ morphologies can have significant impacts on the $\mathrm{BC}$ AOD and $\mathrm{AAOD}$ fractions. As $\mathrm{BC}$ morphologies change from from a fractal dimension of 1.8 to a spherical structure, BC AOD fraction can vary in the range of approximately $4.6 \%-5.8 \%, 5.0 \%$ $-6.2 \%, 5.5 \%-6.9 \%, 4.8 \%-6.0 \%, 9.0 \%-11.1 \%, 10.3 \%-12.7 \%, 9.1 \%-11.2 \%$ in Beijing, Shanghai, Tianjin, Nanjing, Fire Loc1, Fire Loc2, and Fire Loc3, respectively. The variations can be above 25\%. For BC AAOD fraction, the values can vary in the range of approximately $28.1 \%-31.0 \%, 25.0 \%-27.7 \%, 30.2 \%-33.2 \%, 26.5 \%-29.2 \%, 25.4 \%-28.1 \%, 27.0 \%-30.0 \%$, $25.4 \%-28.0 \%$ in Beijing, Shanghai, Tianjin, Nanjing, Fire Loc1, Fire Loc2, and Fire Loc3, respectively. The variations are approximately $10 \%$. Therefore, $\mathrm{BC}$ morphologies should have significant effects on determining the $\mathrm{BC}$ fractions based on the total AOD and AAOD.

Figure 6 shows the AOD of BC with different morphologies. By deriving the BC AOD of three urban cities (Beijing, Hefei, and Taihu), Zhuang et al. (2019) demonstrated that the mean BC AOD in three urban cities was approximately 0.05-0.06. Our simulations are generally in agreement with their results, and the simulated BC AOD varies from approximately 0.01 to approximately 0.12 in the selected urban cities. in Beijing and Tianjin, BC AOD can reach approximately 0.12, while in Shanghai and Nanjing, the maximum BC AOD is approximately 0.07 and 0.1 , respectively. In fire sites, BC AOD is much larger, BC AOD can reach approximately 0.5, 0.9, and 0.6 in Loc1, Loc2, and Loc3, respectively. From Figure 6, we can also see that BC AOD calculated using the sphere model is relatively higher than those using fractal aggregate models. Besides, with the given size distribution, the more compact structure can lead to larger AOD, which is consistent with the findings of Liu and Mishchenko (2005). As shown in Figure 7, in the polluted urban area, a spherical assumption for BC lead to an underestimation of less than 0.03 for AOD, while the underestimation can reach approximately 0.15 in fire sites. The underestimation accounts for a large proportion of BC AOD, which can exceed $20 \%$ of the total BC AOD. Therefore, BC AOD and AAOD suffer a non-neligible uncertainty from $\mathrm{BC}$ morphologies.

Figure 8 shows the calculated BC AAOD using different BC models. Our modeling results show a more compact structure may lead to a smaller AAOD, and this is consistent with the findings of Liu and Mishchenko (2005) for a single BC particle. The reason may be that a more compact structure blocks the light into inner $\mathrm{BC}$, so the smaller absorption efficiency was observed (Kahnert and Devasthale, 2011). By deriving BC AAOD at $440 \mathrm{~nm}$ from AERONET, Shin et al. (2019a) showed that most BC AAOD in Asia are within the range of $0-0.12$. Our simulated BC AAOD at $450 \mathrm{~nm}$ is generally consistent with their findings. At fire sites, BC AAOD at $450 \mathrm{~nm}$ wavelength can reach approximately 0.7. Our results also show that the sphere model can underestimate BC AAOD. As shown in Figure 9, at typical polluted cities, the sphere model can underestimate AAOD by approximately 0.016, while at fire sites, the AAOD underestimation using the sphere model can reach approximately 0.04 . In general, the AAOD underestimation using the sphere model is approximately $8 \%$ of the total BC AAOD. 


\subsection{Impacts of BC morphology on AAE and EAE}

The absorption Ångström exponent (AAE) calculated using different models is shown in Figure 10. Obvious deviations between fractal aggregate models and the sphere model are found for AAE estimation. With more compact structures, smaller AAE can be observed, which agrees with the findings of Li et al. (2016) and Liu et al. (2018). At typical polluted cities, AAE at $450-850 \mathrm{~nm}$ wavelength pair varies from approximately 1.5 to approximately 2.5 , while AAE at fire site can reach as large as approximately 3.0. The observed large AAE is caused by large portions of brown carbon, which significantly absorbs radiation in ultra-violet (UV) and short visible wavelengths. However, as this study mainly focuses on the effects of BC morphologies, the AAE uncertainties caused by OC absorption are not considered in this work. Figure 11 shows that the sphere model can underestimate the AAE by approximately 0.17 , which is approximately $17 \%$ of BC AAE. As AAE is commonly used to determine the aerosol type, $\mathrm{BC}$ morphologies may affect the threshold values for distinguishing the aerosol types.

EAE, as the spectral-dependence of extinction, is widely used to determine the size information of aerosols. Smaller aerosols normally have larger EAE. Figure 12 shows the EAE calculated using different BC models. By using AERONET observation data, in Beijing, Shaheen et al. (2019) showed that the mean EAE at $440-870 \mathrm{~nm}$ in winter was approximately $1.06 \pm 0.36$. The Sun-sky radiometer Observation NETwork (SONET) data conducted by Xie et al. (2015) demonstrated that EAE in the winter of Beijing was commonly within the range of approximately $0.5-1.5$. Our calculated results generally agree with the observation from previous studies. In most cases, the calculated EAE is commonly within the range of $0.5-1.5$, even though some smaller EAE is also observed. In the four typical urban cities, EAE values at $450-850 \mathrm{~nm}$ are similar, and they commonly vary from approximately 0.3 to approximately 1.5 . However, EAE at fire sites is commonly within the range of approximately $1.5-1.85$, which is much larger than the values in the polluted urban area. The reason may be that dominating aerosols in the fire region is commonly occupied by carbonaceous aerosols, which are commonly in fine mode. Compared to AAE, the effects of BC morphologies on the total EAE is relatively small. As shown in Figure 13, the EAE differences between fractal BC and spherical BC are within 0.05 .

\subsection{Impacts of BC morphology on SSA}

SSA, as the ratio of scattering to extinction, is widely used to infer aerosol types. Figure 14 shows the comparison of SSA using different BC models. By using AERONET data, Shin et al. (2019b) showed the mean SSA at $440 \mathrm{~nm}$ was approximately 0.89 - 0.92 in Beijing, and Shaheen et al. (2019) demonstrated mean SSA at $440 \mathrm{~nm}$ was approximately 0.897 in winter in Beijing. At $450 \mathrm{~nm}$, the calculated SSA at typical urban cities is within the range of approximately $0.86-0.92$, which are generally consistent with the observations in previous studies. While in the fire region, SSA varies in a wider range. At $450 \mathrm{~nm}$, SSA at the selected fire sites can vary in the range of approximately $0.75-0.9$, which is a little smaller than that in polluted urban areas due to large portions of carbonaceous aerosols in the fire region.

With more compact structures, SSA presents a larger value, which is consistent with the findings of Kahnert and Devasthale (2011). However, the effects of BC morphologies on total SSA at $450 \mathrm{~nm}$ are not obvious due to the small percentage of BC in the atmosphere. As shown in Figure 15, the overestimations of the spherical BC model for SSA at $450 \mathrm{~nm}$ are generally within 
0.005 at typical polluted cities and within 0.012 at fire sites, which is less than $1 \%$ of the total SSA. However, these values may have relatively larger impacts when evaluating the climate effect of $\mathrm{BC}$, as $\mathrm{BC}$ commonly presents a relatively small value of $0.2-0.4$ (Kahnert and Devasthale, 2011).

\subsection{Impacts of $\mathrm{BC}$ morphology on ARI}

BC ARI at the TOA using different BC models is presented in Figure 16. BC ARI varies in different regions and the reported BC ARI varies in previous studies. For example, a global mean BC ARI of $+1.1 \mathrm{~W} \mathrm{~m}^{-2}$ has been reported by previous studies (Bond et al., 2013), while much larger BC ARI was observed in some regions. Based on situ measurements, Lamb et al. (2018) have estimated the column BC ARI to be +0.48 to $+2.01 \mathrm{Wm}^{-2}$ over South Korea. Zhuang et al. (2018) estimated BC ARI to be $+1.85 \mathrm{Wm}^{-2}$ in East Asia. Much larger BC ARI during December $\left(+15 \mathrm{Wm}^{-2}\right)$ and November $\left(+8 \mathrm{Wm}^{-2}\right)$ over Ahmedabad and Gurushikhar, respectively, were reported by Rajesh and Ramachandran (2018). In eastern China, Zhuang et al. (2019) showed that clear-sky TOA ARI averaged over East Asia $\left(100-130^{\circ} \mathrm{E}, 20-50^{\circ} \mathrm{N}\right)$ were +0.02 to $+1.34 \mathrm{~W} / \mathrm{m}^{2}$ in summer. While in some sites (such as Beijing), the average BC ARI can reach approximately $+4.5 \mathrm{Wm}^{-2}$. Based on different measured BC profiles, Lu et al. (2020) showed BC ARI was within the range of $+3.9-5.1 \mathrm{Wm}^{-2}$ in the Beijing region. Our calculated BC ARI in winter generally agrees with their results. In winter, BC ARI at typically polluted cities commonly varies in the range of approximately $+2-9.0 \mathrm{Wm}^{-2}$, and the mean BC ARI is approximately $+3.5-5 \mathrm{Wm}^{-2}$. While in large fire sites, the mean BC ARI can reach approximately $+7.0 \mathrm{Wm}^{-2}$, and the maximum BC ARI can exceed $+11 \mathrm{Wm}^{-2}$.

Table 1. BC ARI at different sites $\left(\mathrm{Wm}^{-2}\right)$.

\begin{tabular}{ccccc}
\hline Location & $D_{f}=1.8$ & $D_{f}=2.2$ & $D_{f}=2.6$ & Sphere \\
\hline Beijing & +3.83 & +3.72 & +3.59 & +3.47 \\
Shanghai & +4.29 & +4.15 & +3.96 & +3.72 \\
Tianjin & +4.92 & +4.77 & +4.60 & +4.45 \\
Nanjing & +4.03 & +3.90 & +3.73 & +3.54 \\
Fire Loc1 & +5.90 & +5.78 & +5.63 & +5.52 \\
Fire Loc2 & +7.05 & +6.91 & +6.74 & +6.64 \\
Fire Loc3 & +5.23 & +5.12 & +4.99 & +4.91 \\
\hline
\end{tabular}

Generally, with a more compact structure, BC presents smaller ARI at the TOA. Figure 17 shows the difference of BC $\mathrm{ARI}$ at the TOA between fractal aggregate models and the sphere model. In the polluted urban area, the spherical assumption can underestimate BC ARI by approximately $1.0 \mathrm{Wm}^{-2}$, and the underestimation at fire sites can reach approximately 0.6 $\mathrm{Wm}^{-2}$. As shown in Table 1, using the sphere model, mean BC ARI are $+3.47,+3.72,+4.45,+3.54 \mathrm{Wm}^{-2}$ in Beijing, Shanghai, Tianjin, and Nanjing, respectively, while using a fractal aggregate model with a $D_{f}$ of 1.8 , BC ARI can reach $+3.83,+4.29,+4.92,+4.03 \mathrm{Wm}^{-2}$, respectively. The relative deviations are approximately $10.4 \%, 15.3 \%, 10.6 \%, 13.8 \%$ in Beijing, Shanghai, Tianjin, and Nanjing, respectively. In fire sites, the BC ARI differences using different models are relatively smaller. When modifying BC structure from a sphere to a fractal aggregate with a $D_{f}$ of 1.8 , mean BC ARI increases from 
+5.52 to $+5.90 \mathrm{Wm}^{-2},+6.64$ to $+7.05 \mathrm{Wm}^{-2},+4.91$ to $+5.23 \mathrm{Wm}^{-2}$ at Loc1, Loc2, and Loc3, respectively, and the relative uncertainties are approximately 6.9\%,6.2\%, 6.5\%, respectively. By using different measured BC profiles, Lu et al. (2020) showed BC shape can introduce approximately $5 \%$ relative uncertainties in East China. However, our results show that much larger uncertainties can be introduced from BC morphologies. The reason is that in the study of Lu et al. (2020), $D_{f}=2.8$ was assumed for BC aggregates, which is close to spherical shape. This $D_{f}$ value is maybe a little larger than the observed $D_{f}$. Besides, due to different mean solar angles, our results show the ARI uncertainties caused by BC morphologies may vary in different regions. Therefore, the BC morphological effects on the BC ARI should be carefully considered in different regions.

\section{Summary and Conclusions}

In this study, we numerically investigated the effects of $\mathrm{BC}$ morphologies on ARI at four cities in East China and three locations in the northwest US. At $550 \mathrm{~nm}$ wavelength, the spherical BC model can overestimate the AOD up to 0.03 and 0.15 at typical polluted cities in East China and fire regions in the northwest US, respectively. The overestimations roughly account for $20 \%$ of the total BC AOD. Besides, the spherical BC model can underestimate BC AAOD at $450 \mathrm{~nm}$ up to 0.016 and 0.04 at typical polluted cities in East China and fire sites in US, respectively, when modifying BC structure from spheres to fractal aggregates with a $D_{f}$ of 1.8 . The underestimations account for approximately $8 \%$ of the total BC AAOD. Even though BC morphologies have small impacts on total SSA and EAE, their effects on the AAE are rather significant. At $450-850 \mathrm{~nm}$ wavelength pair, AAE is approximately $1.5-2.5$ and $2.0-3.0$ in typical polluted urban area and fire region, respectively. The calculated AAE difference between the spherical BC model and fractal aggregate model can reach approximately 0.17 .

BC morphologies have non-negligible impacts on the BC ARI. Using the spherical BC model, the calculated mean ARI is approximately $+3.47 \mathrm{Wm}^{-2},+3.72 \mathrm{Wm}^{-2},+4.45 \mathrm{Wm}^{-2},+3.54 \mathrm{Wm}^{-2}$ in Beijing, Shanghai, Tianjin, and Nanjing, respectively, while the values increase to approximately $+3.83 \mathrm{Wm}^{-2},+4.29 \mathrm{Wm}^{-2},+4.92 \mathrm{Wm}^{-2}$, and $+4.03 \mathrm{Wm}^{-2}$, respectively, when using a fractal aggregate model with a $D_{f}$ of 1.8 . The relative variations are $10.4 \%, 15.3 \%, 10.6 \%$, and $13.8 \%$, respectively. At fire sites, the uncertainties are smaller but still non-negligible. When modifying $\mathrm{BC}$ from spheres to fractal aggregates with a $D_{f}$ of 1.8 , the mean BC ARI increases from +5.52 to $+5.90 \mathrm{Wm}^{-2},+6.64$ to $+7.05 \mathrm{Wm}^{-2},+4.91$ to $+5.23 \mathrm{Wm}^{-2}$ at Loc1, Loc2, and Loc3, respectively, and the relative variations are approximately $6.9 \%, 6.2 \%, 6.5 \%$, respectively. Therefore, the effects of $\mathrm{BC}$ morphologies on the regional radiative effects should be carefully evaluated.

Acknowledgements. This work was financially supported by the National Natural Science Foundation of China (Grant No. 41925019), the National Key Research and Development Plan under Grant No. 2020YFC1511600, and the Fundamental Research Funds for the Central Universities under Grant No. WK2320000052. RKC and CZ acknowledge support from the US National Science Foundation (AGS-1926817) and the NASA ACCDAM program (NNH20ZDA001N). CZ would like to acknowledge partial support received from the McDonnell International Scholars Academy at Washington University in St. Louis. The look-up tables calculated in this work can be obtained from https://figshare.com/articles/dataset/Look_up_tables_zip/13096241. The PM2.5 data in China was obtained from https://www.aqistudy.cn/historydata/, 
https://doi.org/10.5194/acp-2021-1090

Preprint. Discussion started: 19 January 2022

(C) Author(s) 2022. CC BY 4.0 License.

(c) (1)

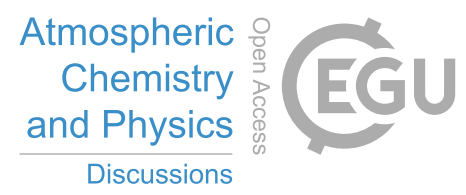

and PM2.5 data in North America can be found from https://www.epa.gov/outdoor-air-quality-data/download-daily-data. FlexAOD can be obtained on request (http://pumpkin.aquila.infn.it/flexaod/). 


\section{References}

Ackermann, I. J., Hass, H., Memmesheimer, M., Ebel, A., Binkowski, F. S., and Shankar, U.: Modal aerosol dynamics model for Europe:

Development and first applications, Atmospheric environment, 32, 2981-2999, 1998.

Adachi, K., Chung, S. H., Friedrich, H., and Buseck, P. R.: Fractal parameters of individual soot particles determined using electron tomography: Implications for optical properties, Journal of Geophysical Research: Atmospheres, 112, https://doi.org/https://doi.org/10.1029/2006JD008296, 2007.

Adachi, K., Zaizen, Y., Kajino, M., and Igarashi, Y.: Mixing state of regionally transported soot particles and the coating effect on their size and shape at a mountain site in Japan, Journal of Geophysical Research: Atmospheres, 119, 5386-5396, https://doi.org/https://doi.org/10.1002/2013JD020880, 2014.

Alexander, D. T., Crozier, P. A., and Anderson, J. R.: Brown carbon spheres in East Asian outflow and their optical properties, Science, 321 , 833-836, 2008.

Bi, L., Lin, W., Wang, Z., Tang, X., Zhang, X., and Yi, B.: Optical Modeling of Sea Salt Aerosols: The Effects of Nonsphericity and Inhomogeneity, Journal of Geophysical Research: Atmospheres, 123, 543-558, https://doi.org/10.1002/2017JD027869, 2018.

Bond, T. C. and Bergstrom, R. W.: Light absorption by carbonaceous particles: An investigative review, Aerosol science and technology, 40, 27-67, 2006.

Bond, T. C., Doherty, S. J., Fahey, D. W., Forster, P. M., Berntsen, T., DeAngelo, B. J., Flanner, M. G., Ghan, S., Karcher, B., Koch, D., Kinne, S., Kondo, Y., Quinn, P. K., Sarofim, M. C., Schultz, M. G., Schulz, M., Venkataraman, C., Zhang, H., Zhang, S., Bellouin, N., Guttikunda, S. K., Hopke, P. K., Jacobson, M. Z., Kaiser, J. W., Klimont, Z., Lohmann, U., Schwarz, J. P., Shindell, D., Storelvmo, T., Warren, S. G., and Zender, C. S.: Bounding the role of black carbon in the climate system: A scientific assessment, Journal of Geophysical Research-Atmospheres, 118, 5380-5552, https://doi.org/10.1002/jgrd.50171, 2013.

Buras, R., Dowling, T., and Emde, C.: New secondary-scattering correction in DISORT with increased efficiency for forward scattering, Journal of Quantitative Spectroscopy and Radiative Transfer, 112, 2028-2034, 2011.

Buseck, S. E. and Buseck, P. R.: Absorbing phenomena (vol 288, pg 989, 2000), Science, 289, 58-58, <GotoISI>://WOS:000088090400023, 2000.

Chakrabarty, R. K., Moosmüller, H., Garro, M. A., Arnott, W. P., Walker, J., Susott, R. A., Babbitt, R. E., Wold, C. E., Lincoln, E. N., and Hao, W. M.: Emissions from the laboratory combustion of wildland fuels: Particle morphology and size, Journal of Geophysical Research: Atmospheres, 111, https://doi.org/https://doi.org/10.1029/2005JD006659, 2006.

Chakrabarty, R. K., Moosmüller, H., Arnott, W. P., Garro, M. A., Slowik, J. G., Cross, E. S., Han, J.-H., Davidovits, P., Onasch, T. B., and Worsnop, D. R.: Light scattering and absorption by fractal-like carbonaceous chain aggregates: Comparison of theories and experiment, Applied optics, 46, 6990-7006, 2007.

Chang, H.-c. and Charalampopoulos, T.: Determination of the wavelength dependence of refractive indices of flame soot, Proceedings of the Royal Society of London. Series A: Mathematical and Physical Sciences, 430, 577-591, 1990.

Chen, C., Fan, X., Shaltout, T., Qiu, C., Ma, Y., Goldman, A., and Khalizov, A. F.: An unexpected restructuring of combustion soot aggregates by subnanometer coatings of polycyclic aromatic hydrocarbons, Geophysical Research Letters, 43, 11,080-11,088, https://doi.org/https://doi.org/10.1002/2016GL070877, 2016. 
Chin, M., Ginoux, P., Kinne, S., Torres, O., Holben, B. N., Duncan, B. N., Martin, R. V., Logan, J. A., Higurashi, A., and Nakajima, T.: "Tropospheric Aerosol Optical Thickness from the GOCART Model and Comparisons with Satellite and Sun Photometer Measurements", Journal of the Atmospheric Sciences, 59, 461-483, https://doi.org/10.1175/1520-0469(2002)059<0461:TAOTFT>2.0.CO;2, 2002.

China, S., Mazzoleni, C., Gorkowski, K., Aiken, A. C., and Dubey, M. K.: Morphology and mixing state of individual freshly emitted wildfire carbonaceous particles, Nature communications, 4, 1-7, 2013.

Coz, E. and Leck, C.: Morphology and state of mixture of atmospheric soot aggregates during the winter season over Southern Asia-a quantitative approach, Tellus B: Chemical and Physical Meteorology, 63, 107-116, 2011.

Cross, E. S., Slowik, J. G., Davidovits, P., Allan, J. D., Worsnop, D. R., Jayne, J. T., Lewis, D. K., Canagaratna, M., and Onasch, T. B.: Laboratory and ambient particle density determinations using light scattering in conjunction with aerosol mass spectrometry, Aerosol Science and Technology, 41, 343-359, 2007.

Curci, G.: FlexAOD: A chemistry-transport model post-processing tool for a flexible calculation of aerosol optical properties, in: Proceedings of the 9th International Symposium on Tropospheric Profiling, pp. 978-90, 2012.

Curci, G., Hogrefe, C., Bianconi, R., Im, U., Balzarini, A., Baró, R., Brunner, D., Forkel, R., Giordano, L., Hirtl, M., et al.: Uncertainties of simulated aerosol optical properties induced by assumptions on aerosol physical and chemical properties: An AQMEII-2 perspective, Atmospheric Environment, 115, 541-552, 2015.

Curci, G., Alyuz, U., Barò, R., Bianconi, R., Bieser, J., Christensen, J. H., Colette, A., Farrow, A., Francis, X., Jiménez-Guerrero, P., Im, U., Liu, P., Manders, A., Palacios-Peña, L., Prank, M., Pozzoli, L., Sokhi, R., Solazzo, E., Tuccella, P., Unal, A., Vivanco, M. G., Hogrefe, C., and Galmarini, S.: Modelling black carbon absorption of solar radiation: combining external and internal mixing assumptions, Atmospheric Chemistry and Physics, 19, 181-204, https://doi.org/10.5194/acp-19-181-2019, 2019.

Dentener, F., Kinne, S., Bond, T., Boucher, O., Cofala, J., Generoso, S., Ginoux, P., Gong, S., Hoelzemann, J., Ito, A., et al.: Emissions of primary aerosol and precursor gases in the years 2000 and 1750 prescribed data-sets for AeroCom, Atmospheric Chemistry and Physics, 6, 4321-4344, 2006.

410 Eggersdorfer, M. L. and Pratsinis, S. E.: The structure of agglomerates consisting of polydisperse particles, Aerosol Science and Technology, 46, 347-353, 2012.

Emmons, L. K., Walters, S., Hess, P. G., Lamarque, J.-F., Pfister, G. G., Fillmore, D., Granier, C., Guenther, A., Kinnison, D., Laepple, T., Orlando, J., Tie, X., Tyndall, G., Wiedinmyer, C., Baughcum, S. L., and Kloster, S.: Description and evaluation of the Model for Ozone and Related chemical Tracers, version 4 (MOZART-4), Geoscientific Model Development, 3, 43-67, https://doi.org/10.5194/gmd-3-43-2010, 2010.

Guenther, A., Zimmerman, P., and Wildermuth, M.: Natural volatile organic compound emission rate estimates for US woodland landscapes, Atmospheric Environment, 28, 1197-1210, 1994.

Guenther, A., Karl, T., Harley, P., Wiedinmyer, C., Palmer, P., and Geron, C.: Estimates of global terrestrial isoprene emissions using MEGAN (Model of Emissions of Gases and Aerosols from Nature), Atmospheric Chemistry and Physics, 6, 3181-3210, 2006.

He, C., Liou, K.-N., Takano, Y., Zhang, R., Levy Zamora, M., Yang, P., Li, Q., and Leung, L. R.: Variation of the radiative properties during black carbon aging: theoretical and experimental intercomparison, Atmospheric Chemistry and Physics, 15, 11967-11980, https://doi.org/10.5194/acp-15-11967-2015, 2015.

He, C., Li, Q., Liou, K.-N., Qi, L., Tao, S., and Schwarz, J. P.: Microphysics-based black carbon aging in a global CTM: constraints from HIPPO observations and implications for global black carbon budget, Atmos. Chem. Phys, 16, 3077-3098, 2016. 
Heinson, W. R., Liu, P., and Chakrabarty, R. K.: Fractal scaling of coated soot aggregates, Aerosol Science and Technology, 51, 12-19, https://doi.org/10.1080/02786826.2016.1249786, 2017.

Hess, M., Koepke, P., and Schult, I.: "Optical Properties of Aerosols and Clouds: The Software Package OPAC", Bulletin of the American Meteorological Society, 79, 831-844, https://doi.org/10.1175/1520-0477(1998)079<0831:OPOAAC>2.0.CO;2, 1998.

Highwood, E. J.: Suggested Refractive Indices and Aerosol Size Parameters for Use in Radiative Effect Calculations and Satellite Retrievals, ADIENT/APPRAISE CP2 Technical Report, DRAFT V2 (5 August 2009), http://www.met.rdg.ac.uk/ adient/refractiveindices.html, last access: 3 January 2019, 2009.

IPCC: Climate change 2013: the physical science basis: Working Group I contribution to the Fifth assessment report of the Intergovernmental Panel on Climate Change, Cambridge university press, 2014.

Kahnert, M.: On the Discrepancy between Modeled and Measured Mass Absorption Cross Sections of Light Absorbing Carbon Aerosols, Aerosol Science and Technology, 44, 453-460, <GotoISI>://WOS:000277436300006, 2010a.

Kahnert, M.: Modelling the optical and radiative properties of freshly emitted light absorbing carbon within an atmospheric chemical transport model, Atmospheric Chemistry and Physics, 10, 1403-1416, < GotoISI >://WOS:000274410000036, $2010 \mathrm{~b}$.

Kahnert, M. and Devasthale, A.: Black carbon fractal morphology and short-wave radiative impact: a modelling study, Atmospheric Chemistry and Physics, 11, 11 745-11 759, https://doi.org/10.5194/acp-11-11745-2011, 2011.

Kahnert, M. and Kanngießer, F.: Modelling optical properties of atmospheric black carbon aerosols, Journal of Quantitative Spectroscopy and Radiative Transfer, 244, 106 849, https://doi.org/https://doi.org/10.1016/j.jqsrt.2020.106849, 2020.

KOylU, U. and Faeth, G.: Structure of overfire soot in buoyant turbulent diffusion flames at long residence times, Combustion and Flame, 89, 140-156, https://doi.org/https://doi.org/10.1016/0010-2180(92)90024-J, 1992.

Lack, D. and Cappa, C.: Impact of brown and clear carbon on light absorption enhancement, single scatter albedo and absorption wavelength dependence of black carbon, Atmospheric Chemistry and Physics, 10, 4207-4220, 2010.

Lamb, K. D., Perring, A. E., Samset, B., Peterson, D., Davis, S., Anderson, B. E., Beyersdorf, A., Blake, D. R., Campuzano-Jost, P., Corr, C. A., Diskin, G. S., Kondo, Y., Moteki, N., Nault, B. A., Oh, J., Park, M., Pusede, S. E., Simpson, I. J., Thornhill, K. L., Wisthaler, A., and Schwarz, J. P.: Estimating Source Region Influences on Black Carbon Abundance, Microphysics, and Radiative Effect Observed Over South Korea, Journal of Geophysical Research: Atmospheres, 123, 13,527-13,548, https://doi.org/10.1029/2018JD029257, 2018.

Lee, K. O., Cole, R., Sekar, R., Choi, M. Y., Kang, J. S., Bae, C. S., and Shin, H. D.: Morphological investigation of the microstructure, dimensions, and fractal geometry of diesel particulates, Proceedings of the Combustion Institute, 29, 647-653, https://doi.org/https://doi.org/10.1016/S1540-7489(02)80083-9, proceedings of the Combustion Institute, 2002.

Li, J., Anderson, J. R., and Buseck, P. R.: TEM study of aerosol particles from clean and polluted marine boundary layers over the North Atlantic, Journal of Geophysical Research: Atmospheres, 108, https://doi.org/https://doi.org/10.1029/2002JD002106, 2003.

Li, J., Liu, C., Yin, Y., and Kumar, K. R.: Numerical investigation on the angstrom ngstrom exponent of black carbon aerosol, Journal of Geophysical Research-Atmospheres, 121, 3506-3518, <GotoISI>://WOS:000375120200027, 2016.

Li, M., Zhang, Q., Streets, D., He, K., Cheng, Y., Emmons, L., Huo, H., Kang, S., Lu, Z., Shao, M., et al.: Mapping Asian anthropogenic emissions of non-methane volatile organic compounds to multiple chemical mechanisms, Atmos. Chem. Phys, 14, 5617-5638, 2014.

Li, M., Zhang, Q., Kurokawa, J.-I., Woo, J.-H., He, K., Lu, Z., Ohara, T., Song, Y., Streets, D. G., Carmichael, G. R., Cheng, Y., Hong, C., Huo, H., Jiang, X., Kang, S., Liu, F., Su, H., and Zheng, B.: MIX: a mosaic Asian anthropogenic emission inventory under the international 
collaboration framework of the MICS-Asia and HTAP, Atmospheric Chemistry and Physics, 17, 935-963, https://doi.org/10.5194/acp17-935-2017, 2017a.

Li, M., Zhang, Q., Kurokawa, J.-i., Woo, J.-H., He, K., Lu, Z., Ohara, T., Song, Y., Streets, D. G., Carmichael, G. R., et al.: MIX: a mosaic Asian anthropogenic emission inventory under the international collaboration framework of the MICS-Asia and HTAP, Atmospheric Chemistry and Physics (Online), 17, 2017b.

Liu, C., Yin, Y., Hu, F., Jin, H., and Sorensen, C. M.: The Effects of Monomer Size Distribution on the Radiative Properties of Black Carbon Aggregates, Aerosol Science and Technology, 49, 928-940, https://doi.org/10.1080/02786826.2015.1085953, 2015a.

Liu, C., Chung, C. E., Yin, Y., and Schnaiter, M.: The absorption Ångström exponent of black carbon: from numerical aspects, Atmospheric Chemistry and Physics, 18, 6259-6273, 2018.

Liu, D. T., Whitehead, J., Alfarra, M. R., Reyes-Villegas, E., Spracklen, D. V., Reddington, C. L., Kong, S. F., Williams, P. I., Ting, Y. C., Haslett, S., Taylor, J. W., Flynn, M. J., Morgan, W. T., McFiggans, G., Coe, H., and Allan, J. D.: Black-carbon absorption enhancement in the atmosphere determined by particle mixing state, Nature Geoscience, 10, 184-U132, <GotoISI>://WOS:000395791400009, 2017.

Liu, F., Zhang, Q., Tong, D., Zheng, B., Li, M., Huo, H., and He, K.: High-resolution inventory of technologies, activities, and emissions of coal-fired power plants in China from 1990 to 2010, Atmospheric Chemistry and Physics, 15, 13 299-13 317, 2015 b.

Liu, L. and Mishchenko, M. I.: Effects of aggregation on scattering and radiative properties of soot aerosols, Journal of Geophysical ResearchAtmospheres, 110, <GotoISI>://WOS:000229988800009, 2005.

Lu, Q., Liu, C., Zhao, D., Zeng, C., Li, J., Lu, C., Wang, J., and Zhu, B.: "Atmospheric heating rate due to black carbon aerosols: Uncertainties and impact factors", Atmospheric Research, 240, 104 891, https://doi.org/https://doi.org/10.1016/j.atmosres.2020.104891, 2020.

Luo, J., Zhang, Y., Wang, F., Wang, J., and Zhang, Q.: Applying machine learning to estimate the optical properties of black carbon fractal aggregates, Journal of Quantitative Spectroscopy and Radiative Transfer, 215, 1 - 8, https://doi.org/https://doi.org/10.1016/j.jqsrt.2018.05.002, 2018a.

Luo, J., Zhang, Y., Wang, F., and Zhang, Q.: Effects of brown coatings on the absorption enhancement of black carbon: a numerical investigation, Atmospheric Chemistry and Physics, 18, 16 897-16914, https://doi.org/10.5194/acp-18-16897-2018, 2018 b.

Luo, J., Zhang, Y., and Zhang, Q.: "A model study of aggregates composed of spherical soot monomers with an acentric carbon shell", Journal of Quantitative Spectroscopy and Radiative Transfer, 205, 184 - 195, https://doi.org/https://doi.org/10.1016/j.jqsrt.2017.10.024, 2018c.

Luo, J., Zhang, Y. M., Zhang, Q. X., Wang, F., Liu, J., and Wang, J. J.: Sensitivity analysis of morphology on radiative properties of soot aerosols, Optics Express, 26, A420-A432, <GotoISI>://WOS:000432457600005, 2018d.

Luo, J., Zhang, Q., Luo, J., Liu, J., Huo, Y., and Zhang, Y.: Optical Modeling of Black Carbon With Different Coating Materials: The Effect of Coating Configurations, Journal of Geophysical Research: Atmospheres, 124, 13 230-13 253, https://doi.org/10.1029/2019JD031701, 2019.

Luo, J., Zhang, Q., Zhang, C., Zhang, Y., and Chakrabarty, R. K.: The fractal characteristics of atmospheric coated soot: Implication for morphological analysis, Journal of Aerosol Science, 157, 105 804, https://doi.org/https://doi.org/10.1016/j.jaerosci.2021.105804, 2021a.

Luo, J., Zhang, Q., Zhang, Y., and Li, Z.: Radiative Properties of Non-spherical Black Carbon Aerosols, pp. 69-124, Springer International Publishing, Cham, https://doi.org/10.1007/978-3-030-87683-8_3, 2021b.

Mackowski, D. W. and Mishchenko, M. I.: Calculation of the T matrix and the scattering matrix for ensembles of spheres, Journal of the Optical Society of America a-Optics Image Science and Vision, 13, 2266-2278, <GotoISI>://WOS:A1996VP77000015, 1996. 

titative Spectroscopy and Radiative Transfer, 112, 2182-2192, <GotoISI >://WOS:000294518300013, 2011.

Martin, R. V., Jacob, D. J., Yantosca, R. M., Chin, M., and Ginoux, P.: Global and regional decreases in tropospheric oxidants from photochemical effects of aerosols, Journal of Geophysical Research: Atmospheres, 108, 2003.

Mayer, B. and Kylling, A.: The libRadtran software package for radiative transfer calculations-description and examples of use, Atmospheric Chemistry and Physics, 5, 1855-1877, 2005.

Mikhailov, E., Vlasenko, S., Podgorny, I., Ramanathan, V., and Corrigan, C.: Optical properties of soot-water drop agglomerates: An experimental study, Journal of Geophysical Research: Atmospheres, 111, 2006.

Mishchenko, M. I., Dlugach, J. M., Yanovitskij, E. G., and Zakharova, N. T.: Bidirectional reflectance of flat, optically thick particulate layers: an efficient radiative transfer solution and applications to snow and soil surfaces, Journal of Quantitative Spectroscopy and Radiative Transfer, 63, 409-432, 1999.

Mishchenko, M. I., Travis, L. D., and Lacis, A. A.: Scattering, absorption, and emission of light by small particles, Cambridge university press, 2002.

Mishchenko, M. I., Dlugach, J. M., and Liu, L.: Linear depolarization of lidar returns by aged smoke particles, Applied optics, 55, 9968-9973, $2016 \mathrm{a}$.

Mishchenko, M. I., Dlugach, J. M., Yurkin, M. A., Bi, L., Cairns, B., Liu, L., Panetta, R. L., Travis, L. D., Yang, P., and Zakharova, N. T.: "First-principles modeling of electromagnetic scattering by discrete and discretely heterogeneous random media", Physics Reports, 632, 1 - 75, https://doi.org/https://doi.org/10.1016/j.physrep.2016.04.002, 2016b.

Moosmüller, H., Chakrabarty, R., and Arnott, W.: Aerosol light absorption and its measurement: A review, Journal of Quantitative Spectroscopy and Radiative Transfer, 110, 844-878, 2009.

Nakao, S., Tang, P., Tang, X., Clark, C. H., Qi, L., Seo, E., Asa-Awuku, A., and Cocker III, D.: Density and elemental ratios of secondary organic aerosol: Application of a density prediction method, Atmospheric environment, 68, 273-277, 2013.

Rajesh, T. and Ramachandran, S.: Black carbon aerosols over urban and high altitude remote regions: Characteristics and radiative implications, Atmospheric environment, 194, 110-122, 2018.

Reddington, C. L., McMeeking, G., Mann, G. W., Coe, H., Frontoso, M. G., Liu, D., Flynn, M., Spracklen, D. V., and Carslaw, K. S.: The mass and number size distributions of black carbon aerosol over Europe, Atmospheric Chemistry and Physics, 13, 4917-4939, 2013.

Saleh, R., Marks, M., Heo, J., Adams, P. J., Donahue, N. M., and Robinson, A. L.: Contribution of brown carbon and lensing to the direct radiative effect of carbonaceous aerosols from biomass and biofuel burning emissions, Journal of Geophysical Research: Atmospheres, 120, 10,285-10,296, https://doi.org/https://doi.org/10.1002/2015JD023697, 2015.

Schwarz, J., Gao, R., Spackman, J., Watts, L., Thomson, D., Fahey, D., Ryerson, T., Peischl, J., Holloway, J., Trainer, M., et al.: Measurement of the mixing state, mass, and optical size of individual black carbon particles in urban and biomass burning emissions, Geophysical Research Letters, 35, 2008.

Seinfeld, J. H., Erdakos, G. B., Asher, W. E., and Pankow, J. F.: Modeling the formation of secondary organic aerosol (SOA). 2. The predicted effects of relative humidity on aerosol formation in the $\alpha$-pinene-, $\beta$-pinene-, sabinene-, $\Delta 3$-carene-, and cyclohexene-ozone systems, Environmental Science \& Technology, 35, 1806-1817, 2001.

Shaheen, K., Shah, Z., Suo, H. L., Liu, M., Ma, L., Alam, K., Gul, A., Cui, J., Li, C. Y., Wang, Y., Khan, S. A., and Khan, S. B.: Aerosol clustering in an urban environment of Beijing during (2005-2017), Atmospheric Environment, 213, 534-547, https://doi.org/10.1016/j.atmosenv.2019.06.027, 2019. 
Shin, S.-K., Tesche, M., Müller, D., and Noh, Y.: Technical note: Absorption aerosol optical depth components from AERONET observations of mixed dust plumes, Atmospheric Measurement Techniques, 12, 607-618, https://doi.org/10.5194/amt-12-607-2019, 2019a.

Shin, S.-K., Tesche, M., Noh, Y., and Müller, D.: Aerosol-type classification based on AERONET version 3 inversion products, Atmospheric Measurement Techniques, 12, 3789-3803, https://doi.org/10.5194/amt-12-3789-2019, $2019 \mathrm{~b}$.

Sorensen, C.: The mobility of fractal aggregates: a review, Aerosol Science and Technology, 45, 765-779, 2011.

Stamnes, K., Tsay, S.-C., Wiscombe, W., and Jayaweera, K.: Numerically stable algorithm for discrete-ordinate-method radiative transfer in multiple scattering and emitting layered media, Applied optics, 27, 2502-2509, 1988.

Stockwell, W. R., Middleton, P., Chang, J. S., and Tang, X.: The second generation regional acid deposition model chemical mechanism for regional air quality modeling, Journal of Geophysical Research: Atmospheres, 95, 16343-16367, https://doi.org/10.1029/JD095iD10p16343.

Streets, D. G., Gupta, S., Waldhoff, S. T., Wang, M. Q., Bond, T. C., and Yiyun, B.: "Black carbon emissions in China", Atmospheric Environment, 35, 4281 - 4296, https://doi.org/https://doi.org/10.1016/S1352-2310(01)00179-0, 2001.

Streets, D. G., Wu, Y., and Chin, M.: Two-decadal aerosol trends as a likely explanation of the global dimming/brightening transition, Geophysical Research Letters, 33,<GotoISI>://WOS:000239597000006, 2006.

Teng, S., Liu, C., Schnaiter, M., Chakrabarty, R. K., and Liu, F.: Accounting for the effects of nonideal minor structures on the optical properties of black carbon aerosols, Atmospheric Chemistry and Physics, 19, 2917-2931, https://doi.org/10.5194/acp-19-2917-2019, 2019.

Wang, Y., Liu, F., He, C., Bi, L., Cheng, T., Wang, Z., Zhang, H., Zhang, X., Shi, Z., and Li, W.: Fractal dimensions and mixing structures of soot particles during atmospheric processing, Environmental Science \& Technology Letters, 4, 487-493, 2017.

Wang, Y., Pang, Y., Huang, J., Bi, L., Che, H., Zhang, X., and Li, W.: Constructing shapes and mixing structures of black carbon particles with applications to optical calculations, Journal of Geophysical Research: Atmospheres, 126, e2021JD034 620, 2021.

Wentzel, M., Gorzawski, H., Naumann, K.-H., Saathoff, H., and Weinbruch, S.: Transmission electron microscopical and aerosol dynamical characterization of soot aerosols, Journal of Aerosol Science, 34, 1347-1370, https://doi.org/https://doi.org/10.1016/S00218502(03)00360-4, intercomparison of Soot Measurement Techniques, 2003.

Wiedinmyer, C., Akagi, S., Yokelson, R. J., Emmons, L., Al-Saadi, J., Orlando, J., and Soja, A.: The Fire INventory from NCAR (FINN): A high resolution global model to estimate the emissions from open burning, Geoscientific Model Development, 4, 625, 2011.

Wild, O., Zhu, X., and Prather, M. J.: Fast-J: Accurate simulation of in-and below-cloud photolysis in tropospheric chemical models, Journal of Atmospheric Chemistry, 37, 245-282, 2000.

Wu, Y., Cheng, T. H., Zheng, L. J., and Chen, H.: A Study of Optical Properties of Soot Aggregates Composed of Poly-Disperse Monomers Using the Superposition T-Matrix Method, Aerosol Science and Technology, 49, 941-949, <GotoISI>://WOS:000366400100005, 2015.

Xie, Y. S., Li, Z. Q., Li, D. H., Xu, H., and Li, K. T.: Aerosol Optical and Microphysical Properties of Four Typical Sites of SONET in China Based on Remote Sensing Measurements, Remote Sensing, 7, 9928-9953, https://doi.org/10.3390/rs70809928, 2015.

Yin, J. Y. and Liu, L. H.: Influence of complex component and particle polydispersity on radiative properties of soot aggregate in atmosphere, Journal of Quantitative Spectroscopy and Radiative Transfer, 111, 2115-2126, <GotoISI>://WOS:000280887400009, 2010.

Yu, P. F., Toon, O. B., Bardeen, C. G., Zhu, Y. Q., Rosenlof, K. H., Portmann, R. W., Thornberry, T. D., Gao, R. S., Davis, S. M., Wolf, E. T., de Gouw, J., Peterson, D. A., Fromm, M. D., and Robock, A.: Black carbon lofts wildfire smoke high into the stratosphere to form a persistent plume, Science, 365, 587-590, <GotoISI >://WOS:000483195200039, 2019.

Yuan, Q., Xu, J., Wang, Y., Zhang, X., Pang, Y., Liu, L., Bi, L., Kang, S., and Li, W.: Mixing state and fractal dimension of soot particles at a remote site in the southeastern Tibetan plateau, Environmental science \& technology, 53, 8227-8234, 2019. 
https://doi.org/10.5194/acp-2021-1090

Preprint. Discussion started: 19 January 2022

(c) Author(s) 2022. CC BY 4.0 License.

(c) (1)

Atmospheric

Chemistry

and Physics

Discussions

Zaveri, R. A. and Peters, L. K.: A new lumped structure photochemical mechanism for large-scale applications, Journal of Geophysical Research: Atmospheres, 104, 30 387-30 415, https://doi.org/10.1029/1999JD900876, 1999.

Zaveri, R. A., Easter, R. C., Fast, J. D., and Peters, L. K.: Model for Simulating Aerosol Interactions and Chemistry (MOSAIC), Journal of Geophysical Research: Atmospheres, 113, https://doi.org/10.1029/2007JD008782, 2008.

580 Zhang, Q., Streets, D. G., Carmichael, G. R., He, K. B., Huo, H., Kannari, A., Klimont, Z., Park, I. S., Reddy, S., Fu, J. S., Chen, D., Duan, L., Lei, Y., Wang, L. T., and Yao, Z. L.: Asian emissions in 2006 for the NASA INTEX-B mission, Atmospheric Chemistry and Physics, 9, 5131-5153, https://doi.org/10.5194/acp-9-5131-2009, 2009.

Zhang, X. Y., Wang, Y. Q., Niu, T., Zhang, X. C., Gong, S. L., Zhang, Y. M., and Sun, J. Y.: Atmospheric aerosol compositions in China: spatial/temporal variability, chemical signature, regional haze distribution and comparisons with global aerosols, Atmospheric Chemistry and Physics, 12, 779-799, https://doi.org/10.5194/acp-12-779-2012, 2012.

Zhuang, B., Li, S., Wang, T., Liu, J., Chen, H., Chen, P., Li, M., and Xie, M.: Interaction between the black carbon aerosol warming effect and East Asian monsoon using RegCM4, Journal of Climate, 31, 9367-9388, 2018.

Zhuang, B. L., Chen, H. M., Li, S., Wang, T. J., Liu, J., Zhang, L. J., Liu, H. N., Xie, M., Chen, P. L., Li, M. M., and Zhao, M.: The direct effects of black carbon aerosols from different source sectors in East Asia in summer, Climate Dynamics, 53, 5293-5310, https://doi.org/10.1007/s00382-019-04863-5, 2019. 

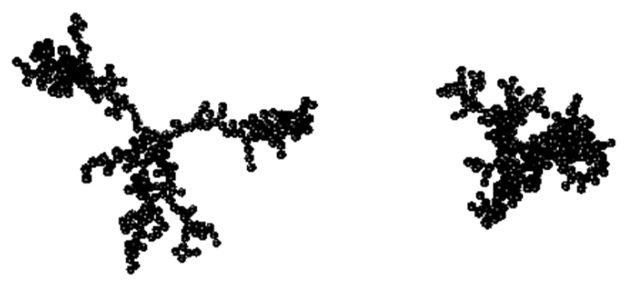

(a) $D_{\mathrm{f}}=\mathbf{1 . 8}$ (b) $D_{\mathrm{f}}=\mathbf{2 . 2}$

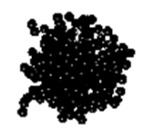

(c) $D_{f}=2.6$

Figure 1. Typical morphologies of fractal BC.
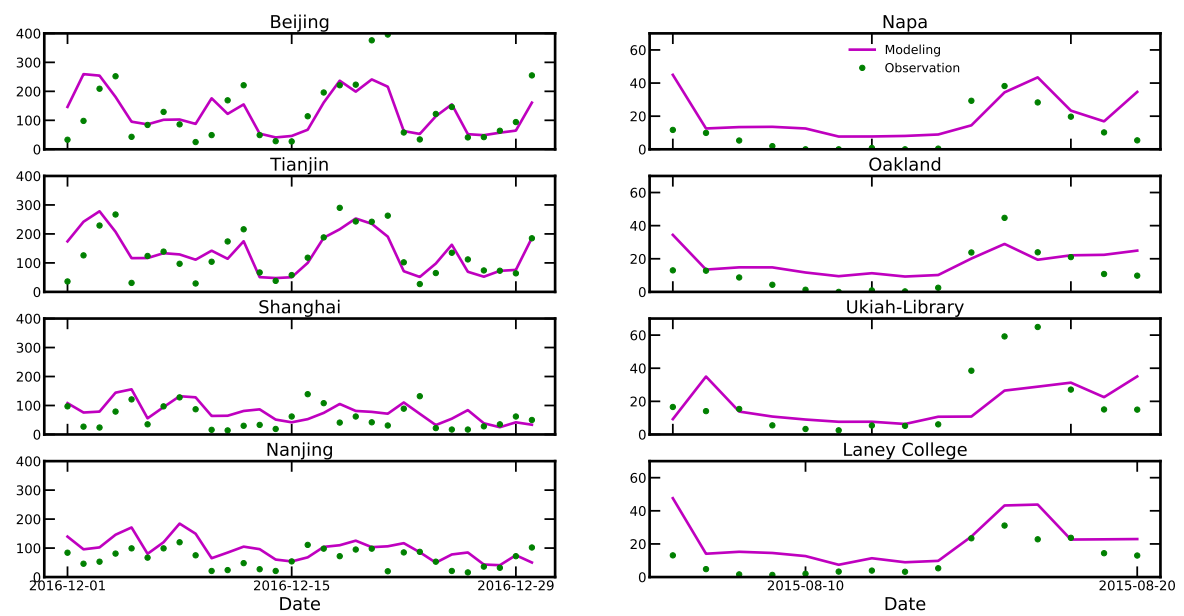

Figure 2. Comparison of measured and calculated PM2.5 concentarions. 

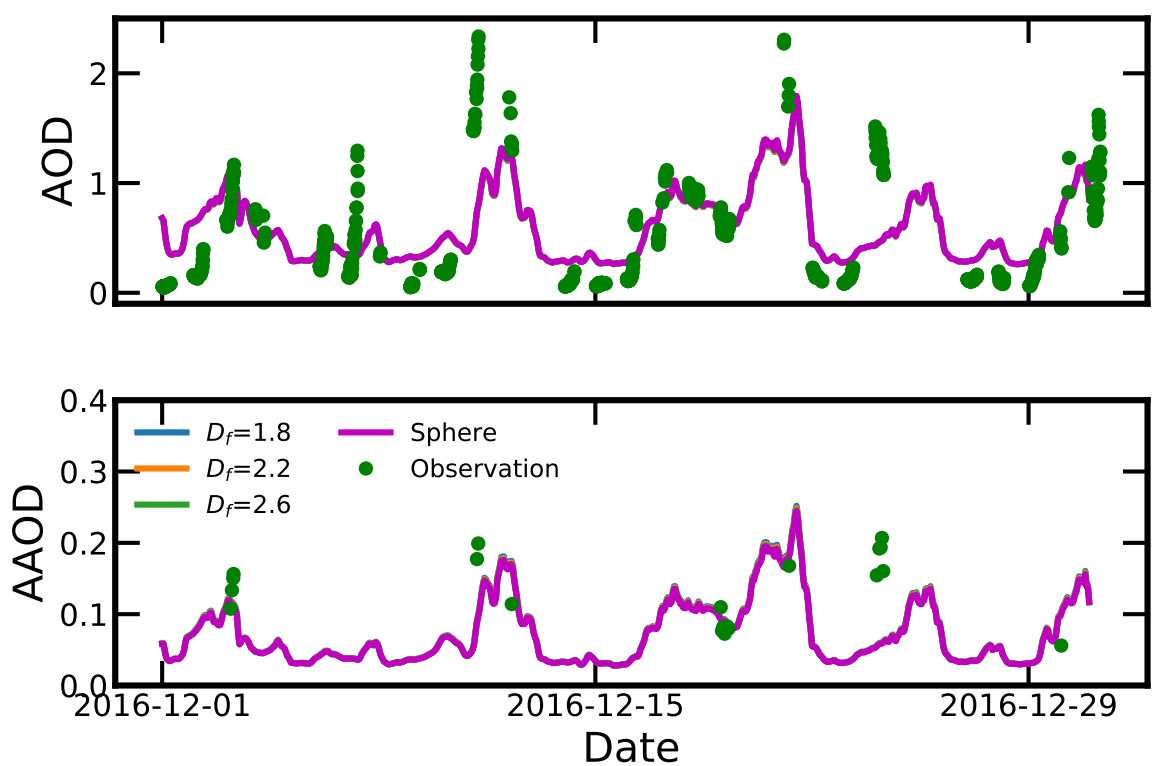

Figure 3. Comparison of measured and calculated AOD and AAOD in Beijing, where $\lambda=500 \mathrm{~nm}$ for AOD. $\lambda=440 \mathrm{~nm}$ and $450 \mathrm{~nm}$ for measured and calculated AAOD, respectively, and the observations were obtained from AERONET.
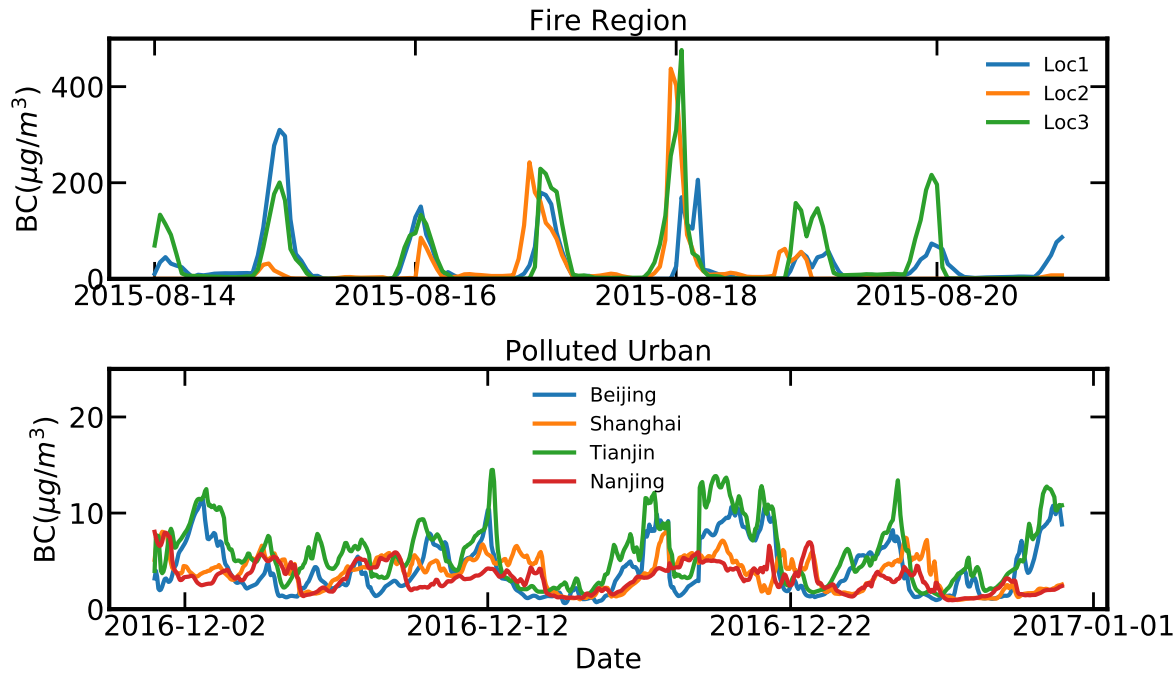

Figure 4. The time series of BC concentritions in typical north Americal and East China. 


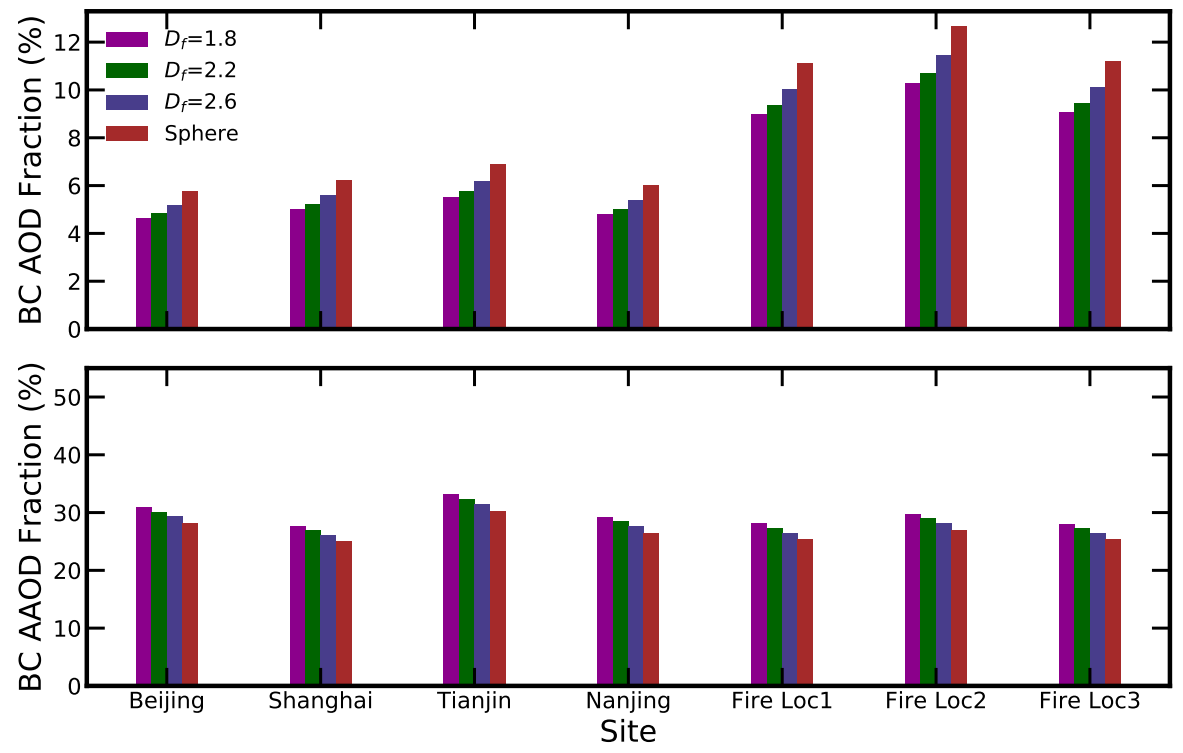

Figure 5. BC AOD $(550 \mathrm{~nm})$ and $\mathrm{AAOD}(450 \mathrm{~nm})$ as a percentage of total AOD and AAOD.
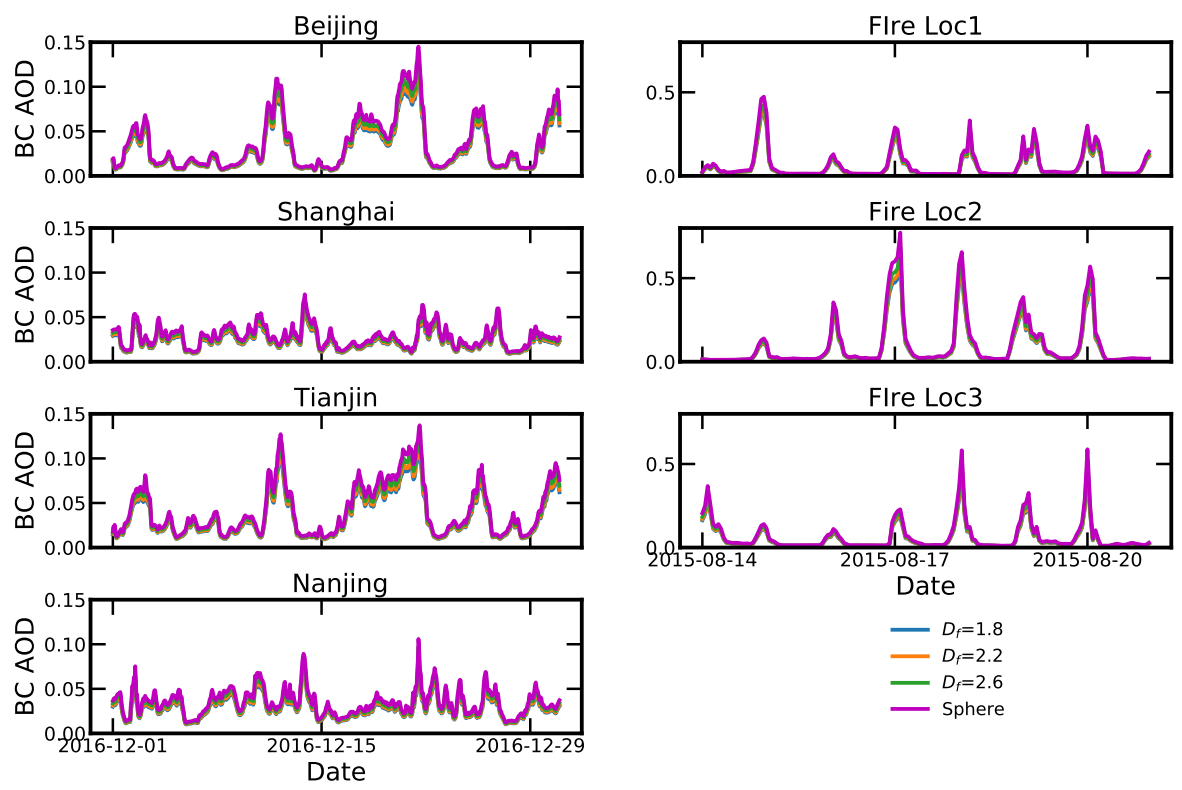

Figure 6. The comparison of BC AOD for different BC morphologies, $\lambda=550 \mathrm{~nm}$. 

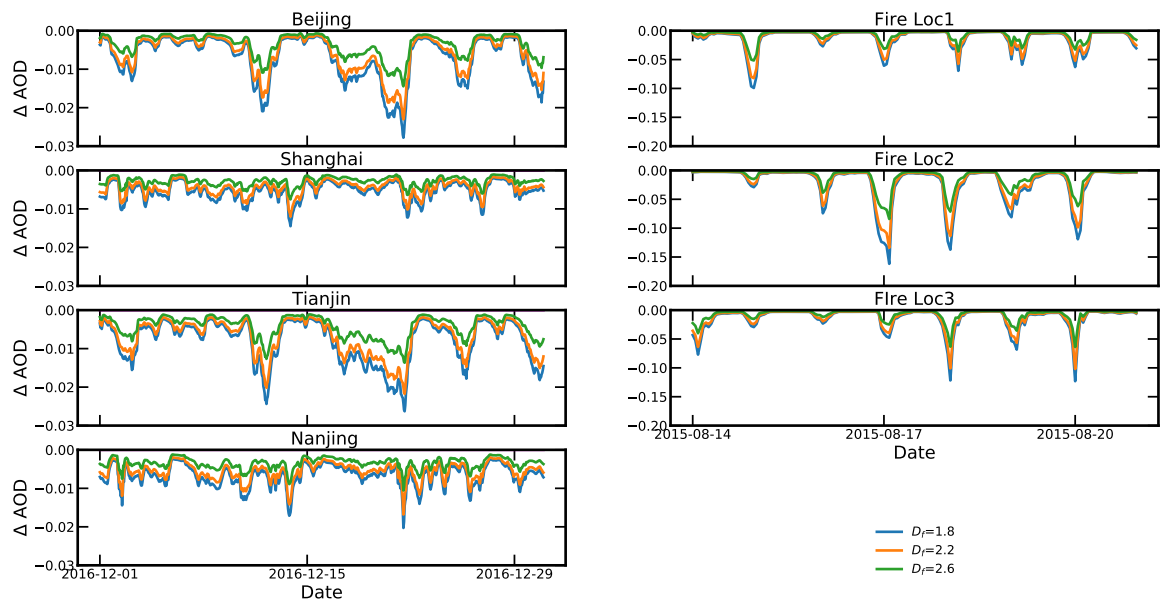

Figure 7. The AOD difference between fractal aggregate models and the sphere model, $\lambda=550 \mathrm{~nm}$.
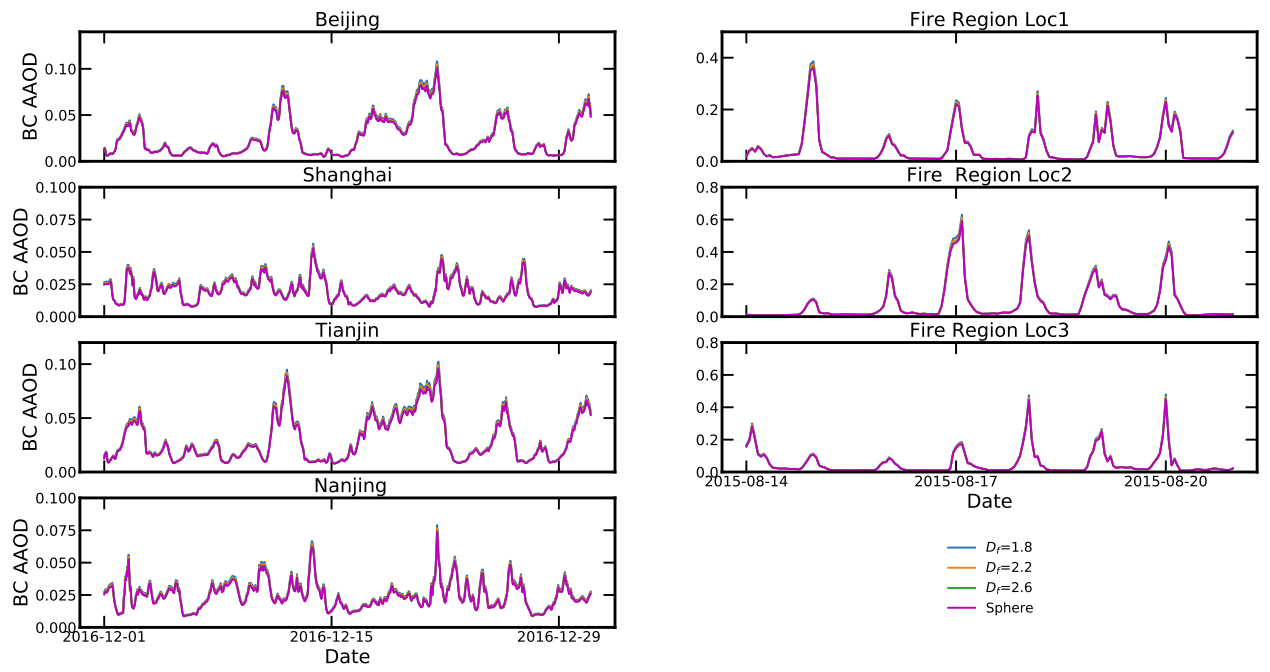

Figure 8. The comparison of BC AAOD for different BC morphologies, $\lambda=450 \mathrm{~nm}$. 

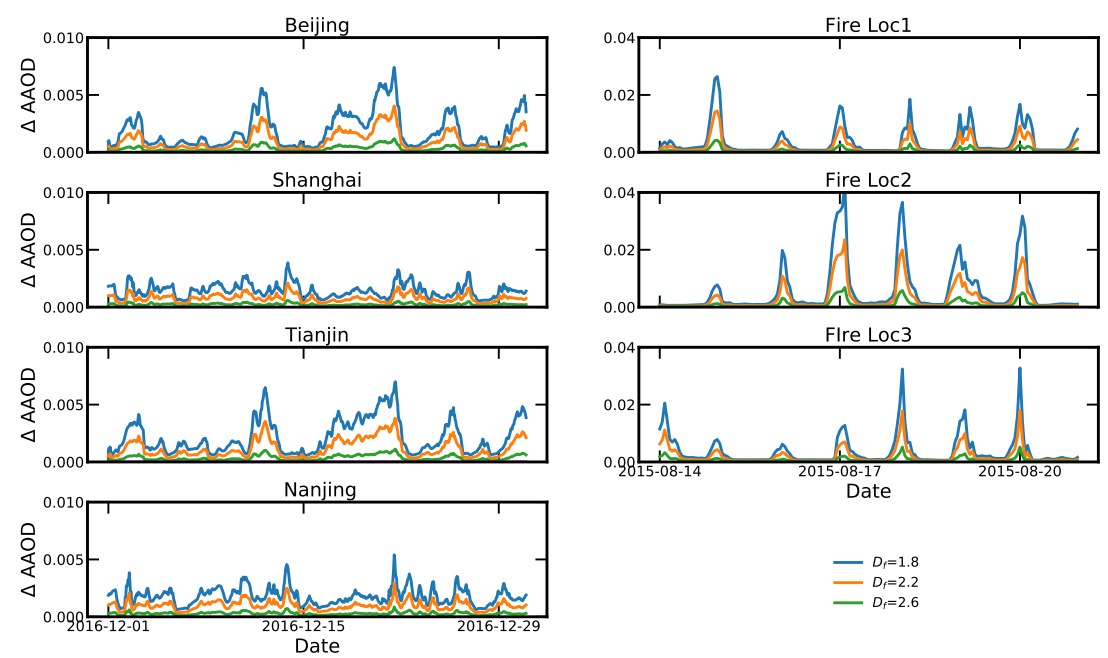

$$
\begin{array}{r}
D_{f}=1.8 \\
-D_{f}=2.2 \\
-D_{f}=2.6
\end{array}
$$

Figure 9. The AAOD difference between fractal aggregate models and the sphere model, $\lambda=450 \mathrm{~nm}$.
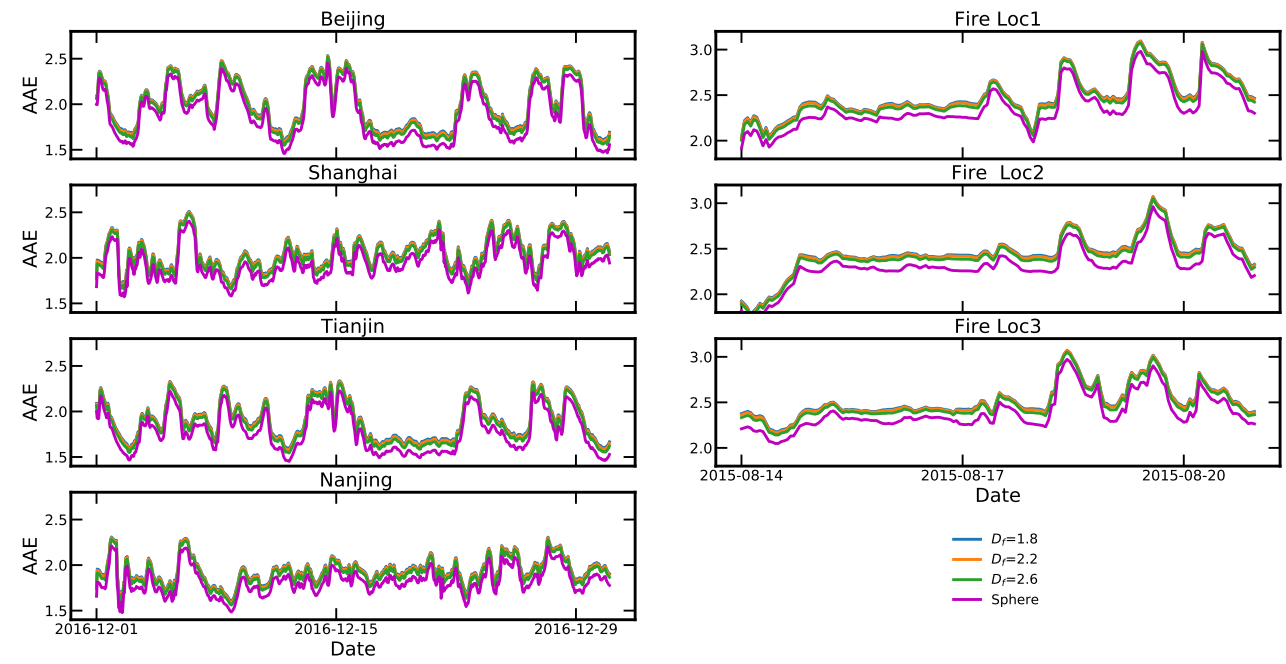

Figure 10. The comparison of BC AAE for different BC morphologies, $\lambda=450 \mathrm{~nm}, 850 \mathrm{~nm}$ pair. 

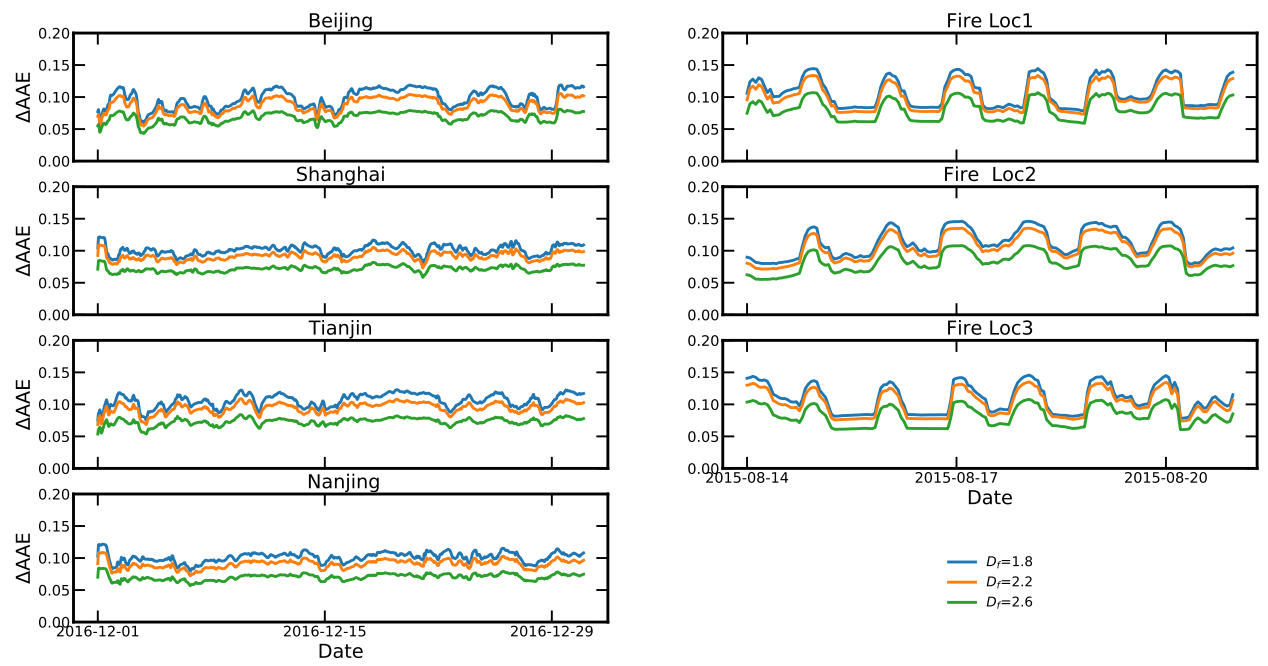

$D_{f}=1.8$

$-D_{f}=2.2$

Figure 11. The AAE differences between fractal aggregate models and the sphere model, $\lambda=450 \mathrm{~nm}, 850 \mathrm{~nm}$ pair.
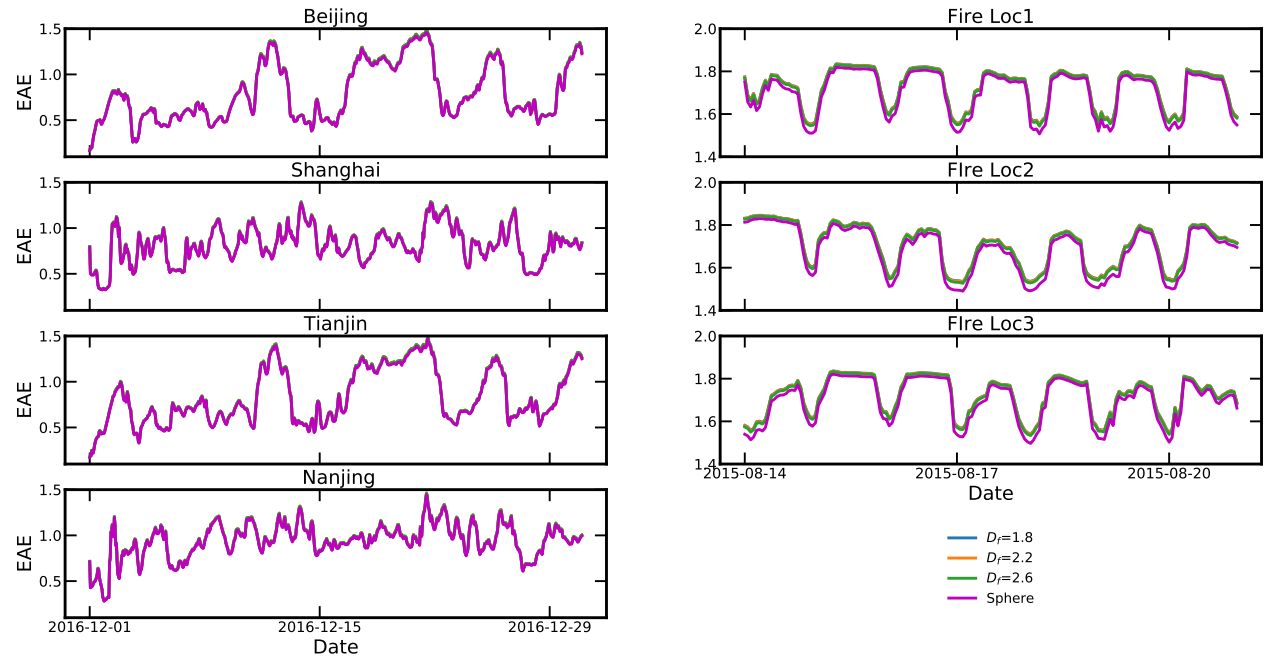

Figure 12. The comparison of BC AAE for different BC morphologies, $\lambda=450-850 \mathrm{~nm}, 850 \mathrm{~nm}$ pair. 

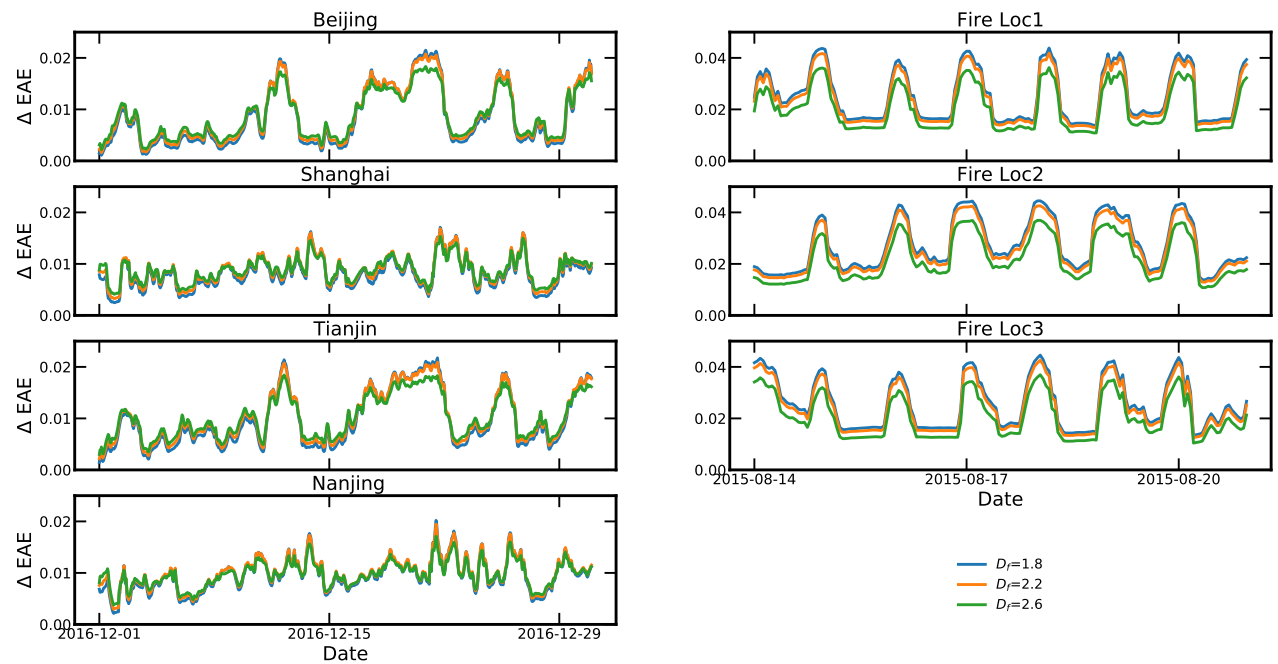

Figure 13. The EAE differences between fractal aggregate models and the sphere model, $\lambda=450 \mathrm{~nm}, 850 \mathrm{~nm}$ pair.
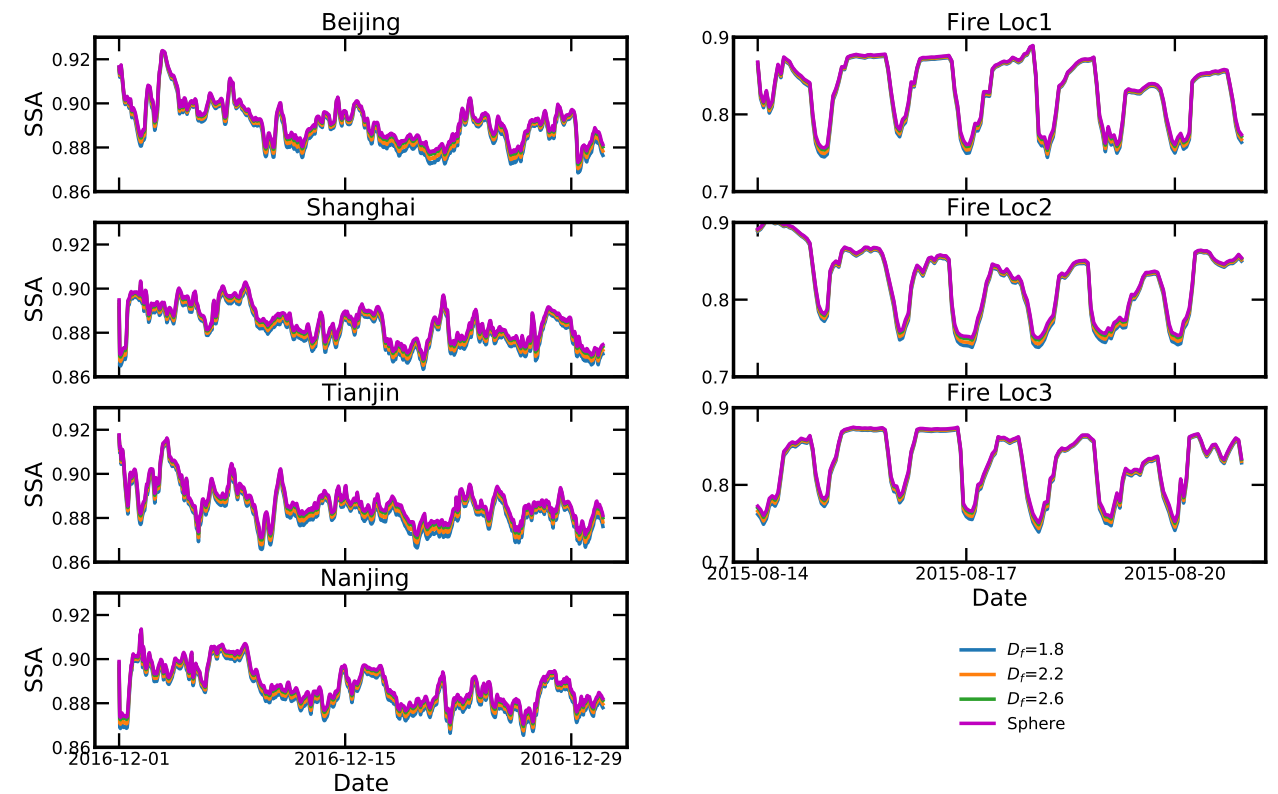

$-D_{f}=1.8$
$-D_{f}=2.2$
$-D_{f}=2.6$
Sphere

Figure 14. The comparison of SSA using different BC models, $\lambda=450 \mathrm{~nm}$. 

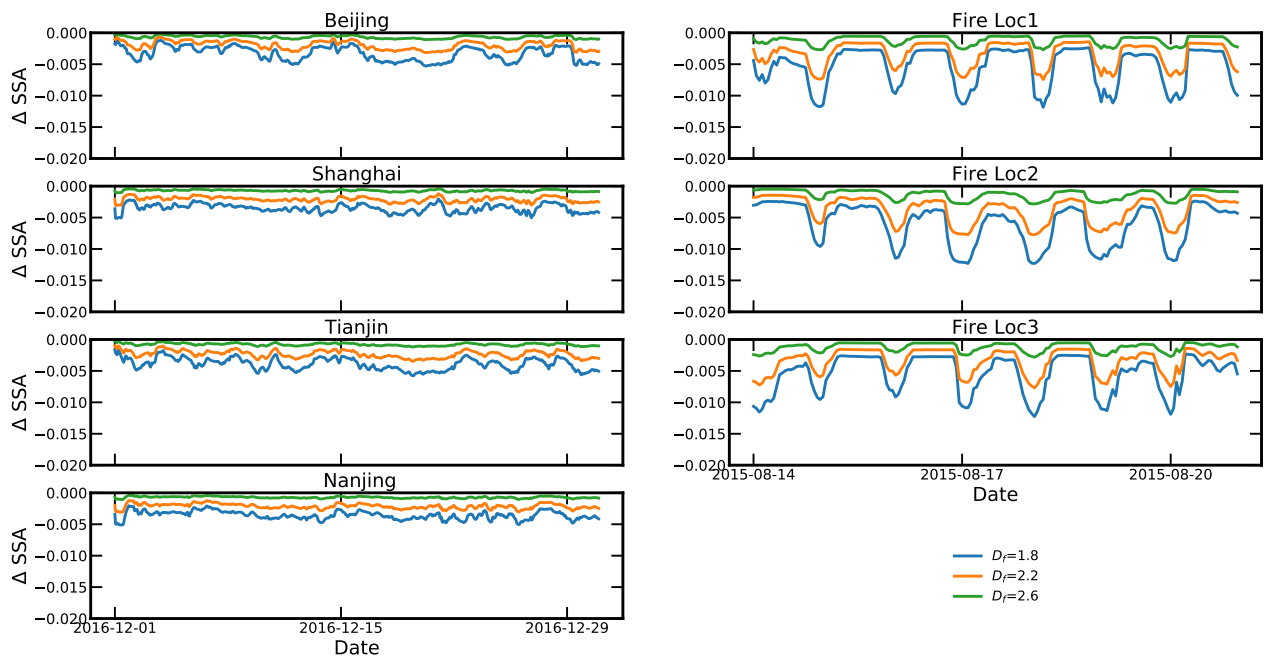

Figure 15. The SSA differences between fractal aggregate models and the sphere model, $\lambda=450 \mathrm{~nm}$.
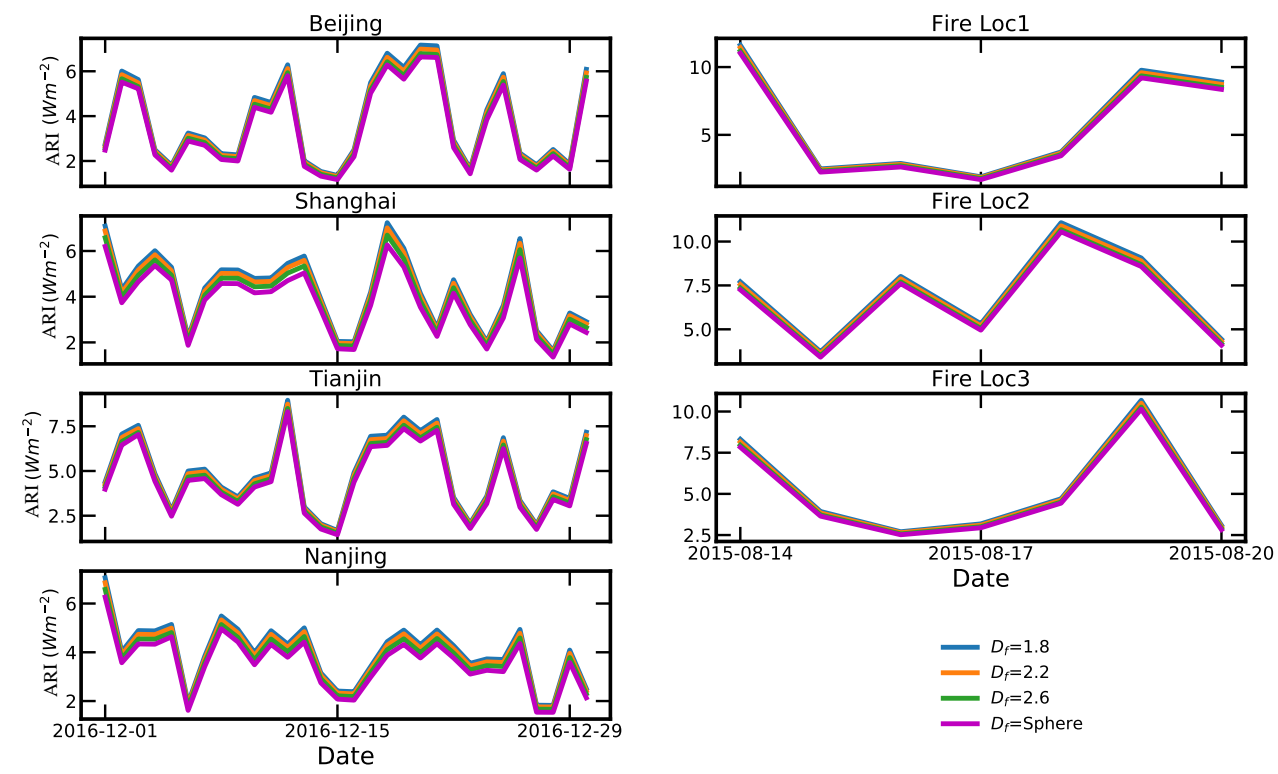

Figure 16. The BC ARI at the TOA calculated using different BC models. 

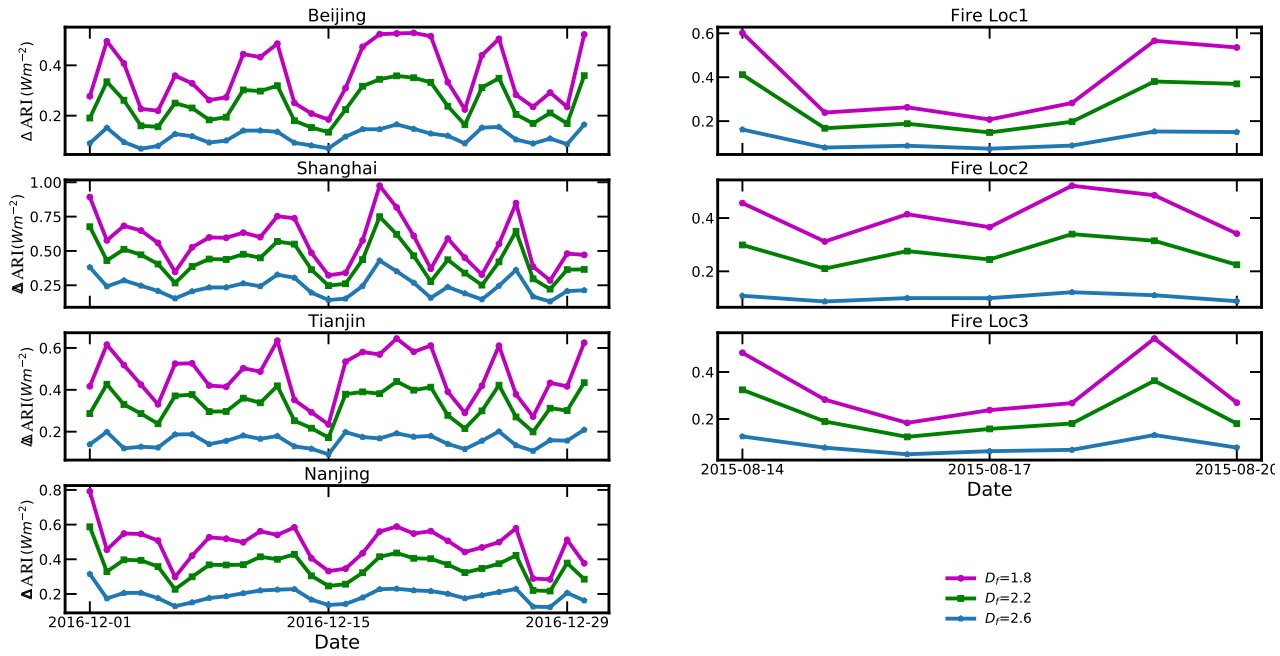

$\simeq D_{f}=1.8$
$\simeq D_{f}=2.2$
$\simeq D_{f}=2.6$

Figure 17. The difference of BC ARI at the TOA between fractal aggregate models and the sphere model. 
https://doi.org/10.5194/acp-2021-1090

Preprint. Discussion started: 19 January 2022

(C) Author(s) 2022. CC BY 4.0 License.

(c) (1)

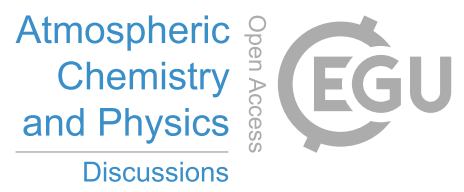

Code availability. The FlexAOD can be requested from Prof. Curci (http://pumpkin.aquila.infn.it/flexaod/).

Data availability. The data can be requested from the corresponding athour.

Author contributions. JL and QXZ conceived the presented idea. JL developed the models, performed the computations, and wrote the paper. ZQL, CZ, YMZ, RKC, YZ verified the simulation methods and results. QXZ revised the paper and supervised the findings of this work. GC developed the FlexAOD model. All authors discussed the results and contributed to the final paper.

Competing interests. The authors declare that they have no conflict of interest. 